\title{
Genetic Trends Estimation in IRRIs Rice Drought Breeding Program and Identification of High Yielding Drought-Tolerant Lines
}

\section{Apurva Khanna}

IRRI: International Rice Research Institute

Mahender Anumalla

IRRI: International Rice Research Institute

Margaret Catolos

IRRI: International Rice Research Institute

Jérôme Bartholomé

IRRI: International Rice Research Institute

Roberto Fritsche-Neto

IRRI: International Rice Research Institute

John Damien Platten

IRRI: International Rice Research Institute

Daniel Joseph Pisano

IRRI: International Rice Research Institute

Alaine Gulles

IRRI: International Rice Research Institute

Ma Teresa Sta. Cruz

IRRI: International Rice Research Institute

Joie Ramos

IRRI: International Rice Research Institute

Gem Faustino

IRRI: International Rice Research Institute

Sankalp Bhosale

IRRI: International Rice Research Institute

Waseem Hussain ( $\nabla$ waseem.hussain@irri.org)

International Rice Research Institute https://orcid.org/0000-0002-6861-0193

Original article

Keywords: Rice, Drought breeding, Historical data, Genetic trends, Breeding panel 
Posted Date: September 22nd, 2021

DOI: https://doi.org/10.21203/rs.3.rs-910539/v1

License: (c) (i) This work is licensed under a Creative Commons Attribution 4.0 International License. Read Full License 
1 Genetic Trends Estimation in IRRIs Rice Drought Breeding Program and Identification of 2 High Yielding Drought-tolerant Lines

3 Apurva Khanna ${ }^{1}$, Mahender Anumalla ${ }^{1}$, Margaret Catolos ${ }^{1}$, Jérôme Bartholomé ${ }^{1,2}$, Roberto 4 Fritsche-Neto ${ }^{1}$, John Damien Platten ${ }^{1}$, Daniel Joseph Pisano ${ }^{1}$, Alaine Gulles ${ }^{1}$, Ma Teresa Sta. 5 Cruz $^{1}$, Joie Ramos ${ }^{1}$, Gem Faustino ${ }^{1}$, Sankalp Bhosale ${ }^{1}$, Waseem Hussain ${ }^{1 *}$

$6{ }^{1}$ Rice Breeding Innovation Platform, International Rice Research Institute (IRRI), Los Baños, 7 Laguna 4031, Philippines.

$8{ }^{2}$ CIRAD, UMR AGAP, Montpellier, France, AGAP, Univ Montpellier, CIRAD, INRA, 9 Montpellier SupAgro, Montpellier, France.

11 * Corresponding author:

12 Waseem Hussain

13 International Rice Research Institute (IRRI),

14 DAPO Box 7777, Metro Manila, Philippines

15 Email: waseem.hussain@irri.org

16 


\section{Abstract}

\section{Background}

19 Estimation of genetic trends using historical data is an important parameter to check the success

20 of the breeding programs. The estimated genetic trends can act as a guideline to target the

21 appropriate breeding strategies and optimize the breeding program for improved genetic gains. In

22 this study, 17 years of historical data from IRRI's rice drought breeding program was used to

23 estimate the genetic trends and assess the success of the breeding program. We also identified

24 top-performing lines based on grain yield breeding values as an elite panel for implementing

25 future population improvement-based breeding schemes.

\section{Results}

27 A two-stage approach of pedigree-based mixed model analysis was used to analyze the data and

28 extract the breeding values and estimate the genetic trends for grain yield under non-stress,

29 drought, and in combined data of non-stress and drought. Lower grain yield values were

30 observed in all the drought trials. Heritability for grain yield estimates ranged between 0.20-0.94

31 under the drought trials, and 0.43-0.83 under non-stress trials. Under non-stress conditions the

32 genetic gain of $0.44 \%(21.20 \mathrm{~kg} / \mathrm{ha} /$ year $)$ for genotypes and $0.17 \%(7.90 \mathrm{~kg} / \mathrm{ha} / \mathrm{year})$ for checks

33 was observed. The genetic trend under the drought conditions exhibited a positive trend with the 34 genetic gain of $0.11 \%(1.98 \mathrm{~kg} / \mathrm{ha} /$ year $)$ for genotypes and $0.55 \%(9.52 \mathrm{~kg} / \mathrm{ha} / \mathrm{year})$ for checks.

35 For combined analysis showed a genetic gain of $0.39 \%(12.13 \mathrm{~kg} / \mathrm{ha} / \mathrm{year})$ for genotypes and $360.60 \%$ (13.69 kg/ha/year) for checks was observed. For elite panel selection, 200 promising lines

37 were selected based on higher breeding values for grain yield and prediction accuracy of $>0.40$.

38 The breeding values of the 200 genotypes formulating the core panel ranged between 2366.17 39 and $4622.59(\mathrm{~kg} / \mathrm{ha})$.

\section{Conclusions}

41 A positive genetic rate was observed under all the three conditions; however, the rate of increase 42 was lower than the required rate of $1.5 \%$ genetic gain. We propose a recurrent selection breeding 43 strategy within the elite population with the integration of modern tools and technologies to 44 boost the genetic gains in IRRI's drought breeding program. The elite breeding panel identified 45 in this study forms an easily available and highly enriched genetic resource for future recurrent 46 selection programs to boost the genetic gains.

47 Key words: Rice, Drought breeding, Historical data, Genetic trends, Breeding panel 


\section{Background}

49 Rice (Oryza sativa L.) is one of the world's major staple crops providing up $20 \%$ of the world's 50 dietary energy and feeding more than 3.5 billion people in the world (Wing et al. 2018). 51 Globally, rice is cultivated in an area of 162Mha with an annual production of $755 \mathrm{mt}$ (FAO 52 2019). Amongst the area under rice cultivation, more than $30 \%$ is under rainfed ecosystems that 53 are subject to severe drought or water-limited conditions (Dixit et al. 2014). Drought is the major 54 limitation for rice production in rainfed ecosystems leading to yield loss of 13-35\% every year 55 (Muthu et al. 2020) and affecting 46Mha of rainfed lowland and 10Mha of upland rice 56 ecosystems in the Asian-Pacific region (Pandey et al. 2007). In Sub-Saharan Africa, drought 57 covers $19 \%$ of the total cultivated rice area and is one of the major causes of low rice grain yields 58 (Van Oort and Zwart, 2018). Low grain yield under drought conditions is further elevated by the 59 pressing climatic changes due to the increasing frequency of drought severity events, thus further 60 limiting the rice productivity (Lenaerts et al. 2019).

61 Direct selection for grain yield under drought has been a major focus of the Rainfed Rice 62 Breeding (RRB) program at the International Rice Research Institute (IRRI). Direct selection for 63 grain yield over secondary traits under drought has been proven effective in improving drought 64 tolerance, and as a result, many drought-tolerant rice varieties have been developed (Kumar et al. 65 2014; Sandhu and Kumar, 2017; Kumar et al. 2018; Bhandari et al. 2020; Dar et al. 2020). 66 However, due to the complex nature of grain yield under drought; mainly characterized by the 67 small and large effect genes; their epistatic interactions, and interaction with environment; and 68 other abiotic stresses, genetic improvement in drought has been a major challenge.

69 Despite these challenges, IRRI has been constantly striving to innovate and develop drought70 tolerant rice varieties and disseminate them to farmers in Africa and Asia-Pacific regions. 71 STRASA (Stress Tolerant Rice for Africa and South Asia) Project (2005-2019) at IRRI, funded

72 by the Bill and Melinda Gates Foundation (BMGF) was one of the most successful research

73 programs that led to the successful development and release of more than 30 high-yielding 74 drought-tolerant rice varieties in Asia and Africa (https://strasa.irri.org/). Under this project, 75 imperative efforts were made to incorporate the major drought-tolerant QTLs (qDTY1.1, 76 qDTY2.1, qDTY2.2, qDTY3.1, qDTY4.1, qDTY12.1 qDTY6.3, etc.,) into the background of the 77 mega rice varieties like IR64, Swarna, and TDK-1 which led to the development of several high 
yielding drought-tolerant rice varieties (Bernier et al. 2007; Venuprasad et al. 2009; Vikram et al.

79 2011; Mishra et al. 2013; Yadaw et al. 2013; Sandhu et al. 2014; Kumar et al. 2014; Henry et al.

80 2015; Dixit et al. 2017; Sandhu and Kumar 2017; Henry et al. 2019; Sandhu et al. 2019;

81 Bhandari et al. 2020; Dixit et al. 2020; Kumar et al. 2020; Majumder et al. 2021; Sandhu et al.

82 2021; Yadav et al. 2021). The most popular drought-tolerant rice varieties include - DRR dhan

83 42, CR Dhan 801, Sahbhagi dhan in India, Sukha dhan 4, Bahuguni dhan 11 in Nepal, and

84 Katihan 2, Katihan 3, Sahod Ulan 15, Sahod Ulan 19 in the Philippines, Yaenelo 4 in Myanmar,

85 MPTSA and ATETE in Malawi, CAR 14 in Cambodia, and BRRI Dhan66, BRRI Dhan 71 in

86 Bangladesh (https://strasa.irri.org/varietal-releases/drought). Despite these endeavors, and the

87 success of the phenotypic selection coupled with marker-based selection strategies, the progress

88 in the genetic improvement of the drought breeding program has been limited. For example, the

89 average estimated rate of genetic gain in rice drought breeding programs in IRRI-India ranges

90 from $0.68 \%$ (under non-stress conditions) to $1.8 \%$ (severe drought conditions) (Kumar et al.

91 2021), which is not sufficient to meet future rice demands. Hence, it is crucial to increase rice

92 productivity at a greater rate to ensure food security and prevent potential food crises in the

93 future (Peng et al. 2004; Li et al. 2018). Aiming 1.5\% or above genetic gain in rice under drought

94 is a huge challenge and is largely hampered by complex genetics of drought-elevated by extreme

95 climatic changes and increase in the frequency of drought events, and availability of limited land

96 to grow rice.

97 To suffice the increasing food demands, it is important to breed drought-tolerant rice varieties

98 with expected genetic gains. Rice breeders must be smart to implement the advanced tools and 99 technologies into the existing breeding pipeline and re-design it for accelerating genetic gains.

100 The Accelerated Genetic Gain in Rice Alliance (AGGRi) project funded by BMGF is one of the 101 IRRI's ongoing projects aimed at modernizing the IRRI-NARES (National Agriculture Research 102 Extension System) rice breeding program and accelerate the genetic gain from the current level 103 of less than $1 \%$ to at least $1.5 \%$ or above annually.

104 Genetic gain is an important parameter to check the progress and success of the breeding 105 programs. The genetic gain estimations can be associated with the ongoing breeding program to 106 target the appropriate breeding strategies and act as a guide to optimize and modernize the rice 107 breeding program for accelerated genetic gains. The rate of genetic gain in the IRRI's rice 108 drought breeding program has never been estimated. On the other note, the historical or current 
109 elite breeding lines are an important genetic resource that can be directly used in the population

110 improvement-based breeding programs to improve the genetic gains. Further, integrating the 111 modern genomic tools and technologies with the population improvement-based breeding 112 programs using elite lines as a genetic resource will boost the genetic gains (Xu et al. 2017). 113 However, it is important to select the appropriate lines from the historical breeding pool 114 representing the overall genetic diversity in the breeding pool and should have high mean 115 performance for grain yield and possess the major genes or haplotypes for mendelian traits.

116 Thus, to assess genetic gains in the IRRI's rice drought breeding program and select the valuable 117 elite lines as a future genetic resource we conducted this study to 1) estimate the genetic trends 118 for grain yield in IRRI's rice drought breeding program by leveraging 17 years of historical data 119 from the advanced yield trials (AYT) managed under drought and normal conditions and, 2) 120 identify high yielding drought-tolerant lines based on the grain yield breeding values as a future 121 genetic resource for recurrent selection program. The AYT trials included premium released 122 varieties from IRRI globally, therefore, are the potential reservoirs to select some of the high123 yielding drought-tolerant lines as a future genetic resource.

\section{Materials and Methods}

\section{Description and Pre-processing of Historical Data}

126 For this study, historical data from yield trials conducted under normal (non-stress) and drought 127 conditions (at the reproductive stage) at IRRI, Philippines from 2003 to 2019 (17 years) were 128 used. The trials in each year were conducted in two seasons- dry (from January to April) and wet 129 (from late June to September) season. The combination of year, season and treatment were 130 treated as a trial or environment. In total the historical data harbored 19,916 data points with 1312,497 unique lines. The data was pre-processed, and the quality of phenotype records was 132 checked initially to ensure high-quality trials and phenotypes are retained for downstream 133 analysis. The data was checked for extreme or unexpected values, missing percentages, and valid 134 experimental design. The trials having more than $20 \%$ of missing data for grain yield, lack of 135 replications, or proper experimental design were dropped initially. Further, the extreme 136 observations were checked in the data before outlier detection as they may increase the error

137 variance which may affect the performance of the outlier detection (González et al. 2018). After 138 preprocessing data was checked for outlier detection using the Bonferroni-Holm test (Bernal- 
Vasquez et al. 2016; Philipp et al. 2019). The 88 data points detected as outliers were removed

140 from the data to make sure only high-quality data points are retained for reliable estimates. In

141 total 53 trials harboring 19,828 data points with 2,490 unique lines were retained for downstream

142 analysis. The complete information on the trials including the year, season, treatment,

143 experimental design, number of plots, replications, and blocks are provided in the Additional file

144 1: Table S1. Trials were performed in varied experimental designs including alpha lattice,

145 augmented randomized complete block, and randomized complete block designs (RCBD). Three

146 major agronomic traits days to 50\% flowering (DTF), plant height (PH), and grain yield ( $\mathrm{kg} / \mathrm{ha})$

147 were retrieved and used for downstream analysis.

\section{Pedigree Data Extraction}

149 The pedigree data of 2,490 unique lines were extracted from the breeding data management 150 system (Breeding 4 Results (B4R), 2021) which has the passport to comprehensive information 151 of the genotype, phenotype, and pedigree data of breeding lines. Additional information on the 152 parents and grandparents up to seven generations, cross-type for each line, and breeding strategy 153 were extracted using the IRRI genealogy management system (McLaren et al. 2005; Collard et 154 al. 2019) using customized R scripts.

\section{Statistical Modelling of Phenotypic Data}

156 A two-stage approach of mixed model analysis was used to analyze the data and extract the 157 breeding values for grain yield, DTF, and PH (Piepho et al. 2008; Piepho et al. 2012; Smith and 158 Cullis 2018) under non-stress, drought, and by analyzing drought and non-stress together. The 159 two-stage approach was adopted to account for different experimental designs across the 160 environments (Damesa et al. 2017). In the first stage, per year adjusted means as BLUEs for each 161 genotype were estimated for each environment. The mixed model used consisted of genotypes as 162 fixed effects, and season replications and or blocks were used as random effects. BLUEs for each 163 genotype per year was obtained using the following linear mixed model:

$$
y_{i j k l}=\mu+g_{i}+r_{j}+b_{k}+s_{l}+\varepsilon_{i j k l}
$$

164 where, $y_{i j k l}$ represents adjusted means for $i$ th observation in $j$ th replication, $k$ th block and $l$ th 165 season, $\mu$ is the overall mean, $g_{i}$ is the fixed effect of $i$ th genotype, $r_{j}$ is the random effect of 166 replications in each trial, $b_{k}$ is the random block effect, $s_{1}$ is the random effect for season and 
$167 \varepsilon_{i j k l}$ is the residual error. The random effects were distributed independently and identically. In 168 this model, DTF was used as a covariate for reducing the error on yield caused due to the 169 presence of different maturity genotypes. The above model was used for the trials which were 170 performed using an alpha-lattice breeding design. For environments with augmented RCBD 171 experimental design, replications were considered equal to blocks, and hence block effect was 172 removed. Likewise, BLUEs and standard error values were calculated respectively for each 173 genotype per year for the DTF and PH traits using equation 1.

174 The combined analysis using a linear mixed model was used to extract the single value BLUEs 175 adjusted across the non-stress and drought treatments. The model used follows as:

$$
y_{i j k l m}=g_{i}+r_{j}+b_{k}+s_{l}+t_{m}+\varepsilon_{i j k l m}
$$

176 all the terms are described in equation 1 except the $t_{m}$ which is the fixed effect of $m$ th treatment 177 (non-stress and drought). We assume different variances across non-stress and drought 178 treatments in the model to get the adjusted means.

179 Heritabilities for grain yield in each environment across non-stress and drought conditions were 180 calculated for each environment (Piepho and Mohring 2007). The same model described above 181 was used to calculate the heritability with genotypes as a random effect. The equation to 182 calculate heritability follows as:

$$
H^{2}=1-\frac{\bar{V}_{B L U P}}{2 \sigma_{g}^{2}}
$$

183 where, $\bar{V}_{B L U P}$ is the mean-variance difference of two BLUPs and $\sigma^{2} \mathrm{~g}$ is the variance of 184 genotypes.

185 In the second stage analysis, a pedigree-based mixed model approach was used to extract the 186 breeding values each in non-stress, drought, and combined data using weighted BLUEs as 187 response variable (Mohring and Piepho 2009). The weighted BLUEs were used to take care of 188 the heterogeneous error variance and weights were calculated by the inverse of the squared 189 standard error of BLUEs. The model used was:

$$
y_{i j}=\mu+g_{i}+y e_{j}+\varepsilon_{i j}
$$


191 where $y_{i j}$ is the weighted BLUE value for $i$ th observation in $j$ th year, $\mu$ is the overall mean, $g_{i}$ is 192 the random effect of $i$ th genotype with $\mathrm{g}_{\mathrm{i}} \sim \mathrm{N}\left(0, \mathrm{~A} \sigma_{\mathrm{g}}^{2}\right)$ where $\sigma_{\mathrm{g}}^{2}$ is the genetic variance and $\mathrm{A}$ is 193 the additive genetic relationship matrix based on pedigrees, $y e_{j}$ is the random effect of year, and $194 \varepsilon_{i j}$ is the residual error, with $\varepsilon_{i j} \sim \mathrm{N}\left(0, \mathrm{R} \sigma_{\varepsilon}^{2}\right)$, where $\mathrm{R}$ is the identity error covariance matrix and

$195 \sigma_{\varepsilon}^{2}$ is the error variance. The reliability of the breeding values (Isik et al. 2017) of each genotype 196 was estimated using the following equation:

$$
r=1-\frac{P E V}{\sigma_{g}^{2}}
$$

197 Two-stage mixed model data analysis was performed in the R software (R Core Team, 2020).

198 using the ASReml-R 4 package (Butler et al. 2017). The R package AGHMatrix was used for 199 constructing the pedigree A-matrix (Amadeu et al. 2016). The analytical pipeline and codes are 200 available on the GitHub (https://github.com/whussain2/Genetic_Trend_Rice_Drought)

\section{Estimation of the Genetic Trends}

202 The genetic gain was estimated separately for three conditions: a) non-stress (normal conditions) 203 trials, b) drought trials, and c) combined data (adjusted means across non-stress and stress trials). 204 For the genetic gain trend, breeding values were regressed on the year of origin of the line. The 205 genetic trend was also estimated for released varieties and checks by regressing the breeding 206 value of checks on the year of origin in non-stress trials, drought trials, and combined data.

\section{Identification of Breeding Panel}

208 Adjusted breeding values obtained from mixed-model analysis across non-stress and stress data 209 were used for the identification of elite genotypes as a future breeding resource. A total of 200 210 lines were selected from the 2,490 unique historical lines based on the higher breeding values 211 and prediction accuracy of $>0.4$. In addition to the lines with higher breeding values and 212 prediction accuracy for grain yield, lines with key QTLs for key biotic and abiotic stresses. To 213 make sure genotypes selected are diverse and represent the whole collection of lines in historical 214 lines, the pedigree matrix was used in the analysis to account for similarity among the lines. The 215 similarity and diversity among the selected lines in comparison to the whole collection were 216 visualized through bi-plot. For bi-plot, principal component analysis (PCA) was performed on 217 the pedigree-based relationship matrix using the princomp() function in $\mathrm{R}$ software. Bi-plot was 218 visualized using the factoextra $\mathrm{R}$ package (Kassambara and Mundt, 2017) 


\section{Results}

\section{Descriptive Features of Historical Drought Data}

221 The three main traits grain yield, PH, and DTF grown under normal and drought conditions were 222 used for analysis. The difference in phenotypic trait values for all three traits was observed in 223 normal and drought conditions. The difference in trait value was also evident across the years. 224 The raw mean grain yield under the normal conditions ranged from 3000-12000 (kg/ha) as 225 compared to the drought conditions 1360-5600 (kg/ha) (Fig. 1a). In each trial, lower yield values

226 were observed under drought conditions as compared to trials under normal conditions indicating 227 the impact of drought on the phenotypes. For DTF we observed higher values under drought 228 conditions (63-129 days) as compared to the trials under normal conditions (60-119 days) 229 (Kazan and Lyons 2016; Shavrukov et al. 2017). Further, we observed a wide distribution in 230 DTF for the genotypes, and genotypes were classified into three maturity groups i.e., early (85231109 days), medium (110-124 days), and late (DTF>125 days) (Additional file 1: Fig. S1). The 232 DTF of $68 \%$ of the lines from the complete unique set of lines under drought implication falls 233 into the medium duration maturity category. The remaining genotypes make up 15\% and $16 \%$ 234 for early and late duration groups, respectively. Similarly, under the non-stress conditions, the 235 percentage of lines falling into three maturity categories were, early (15\%), medium (76\%), and 236 late (9\%) respectively. Because of the wide distribution in DTF, we used DTF as covariate in the 237 phenotypic data modeling to adjust for the grain yield. Similarly, for PH we observed a wide 238 distribution in phenotypic values and PH in the data set ranged from 40-195 (cm) under normal 239 conditions and 40-90 (cm) under drought conditions (Additional file 1: Fig. S2). The dataset has 240 ample diversity among the tested genotypes having a diverse range for PH between $40 \mathrm{~cm}$ to 195 $241 \mathrm{~cm}$. Low plant height was observed under drought conditions, consistent with the previous 242 reports (Ahmadikhah and Marufinia 2016; Mishra and Panda 2017; Hussain et al. 2018; Panda et 243 al. 2021). Heritability for grain yield estimates ranged between 0.20-0.94 under the drought trials 244 and 0.43-0.83 under normal growing trials for the non-stress trials (Fig. 1b). Lower heritability 245 was observed in most of the drought trials. Reduction in heritability under drought conditions is a 246 common phenomenon (Henry et al. 1997, Kumar et al. 2007) which indicates that genotypes are 247 not able to express the higher genetic potential for grain yield.

\section{Historical Data Connectivity}


Historical data sets usually have very low connectivity as new lines are being tested every year, 250 and only a limited number of times the new lines are being tested. In the current data set, we 251 observe appropriate connectivity of the different genotypes across the years (Fig. 1c), and this 252 connectivity was mainly created by long-term checks (IR64, Swarna, Sahbhagi Dhan, IRRI 154)

253 across the years. Further, over the breeding cycles and years, the superior genotypes were 254 forwarded and re-tested in the succeeding years which made the dataset well connected to 255 previous years (Additional file 1: Fig. S3) Further to ensure good connectivity and get reliable 256 estimates of the breeding values, relationship matrix (Additional file 1: Fig. S4) based on 257 pedigrees of 2,970 unique lines was incorporated in the second stage of mixed model analysis.

\section{Estimation of Breeding Values}

259 Breeding values obtained from second-stage analysis by fitting a pedigree matrix were used to 260 estimate the genetic trends and used to identify the best lines based on higher breeding values for 261 the formulation of the core panel. The range of the breeding values for the genotypes under 262 drought stress was between $642.79-3,267.60$ ( $\mathrm{kg} / \mathrm{ha}$ ). Under the normal growing conditions, the 263 breeding values of the genotypes ranged between $3,447.93-6,933.32(\mathrm{~kg} / \mathrm{ha})$. The breeding 264 values adjusted across drought and normal growing conditions ranged between 1,026.93$2654,622.59(\mathrm{~kg} / \mathrm{ha})$. The histogram of the breeding values along with the mean and standard 266 deviations is given in the (Additional file 1: Fig. S5).

\section{Estimation of Genetic Trends}

268 The genetic trend was estimated for the genotypes and, also for checks and released varieties in 269 normal growing conditions, drought conditions, and in combined data. Under normal growing 270 conditions, the genetic gain of $0.44 \%$ with a yield advantage of $21.20 \mathrm{~kg} / \mathrm{ha}$ per year was 271 observed for genotypes (Fig. 2a), and genetic gain of $0.17 \%$ was observed for checks and 272 released lines representing increase of $7.90 \mathrm{~kg} / \mathrm{ha}$ per year (Fig. 3a). The genetic trend under the 273 drought conditions exhibited a positive trend with a genetic gain of $0.11 \%$ for genotypes (Fig. $2742 \mathrm{~b}$ ) and $0.55 \%$ for released lines (Fig. 3b). Yield advantages of $1.98 \mathrm{~kg} / \mathrm{ha}$ for genotypes and $2759.52 \mathrm{~kg} / \mathrm{ha}$ for checks was observed. The regression estimates for combined analysis (adjusted 276 breeding values across normal and drought growing conditions) showed a genetic gain of $0.39 \%$ 277 for genotypes (Fig. 2c) and $0.60 \%$ (Fig. 3c) for checks with a yield advantage of $12.13 \mathrm{~kg} / \mathrm{ha}$ for 278 genotypes and $13.69 \mathrm{~kg} / \mathrm{ha}$ for checks. 
279 Further we divide the genetic gain trend estimation in time periods of 2003-2012 and 2013-2019

280 based on the breeding strategies adopted by the drought breeding program at IRRI. Genetic gain was $0.31 \%$ (under non-stress condition) and $0.21 \%$ (under stress condition) higher in the period 2013-2019 as compared to period 2003-2012 (Additional file 1: Fig. S6)

\section{Comparison of Breeding Values}

284 We compared the breeding values of the popular checks and the released varieties from IRRI, to assess their performance under three conditions viz., stress, non-stress, and combined stress and non-stress. This assessment was undertaken with the overview to deduce the best performers among the released IRRI lines. The performance of the released varieties was superior to the popular checks under all three conditions (Fig. 3a-c). The varieties IRRI 188, IRRI 199, and IRRI 200 had superior breeding values of 2,547.19 (kg/ha), 2,420.70 (kg/ha), and 2,490.97 $(\mathrm{kg} / \mathrm{ha})$, respectively, compared to popular checks and other released varieties when estimated under the drought stress conditions (Fig. 3a). These varieties were released in the years 2015 and 2016, depicting growth of the breeding program over the preceding released varieties developed in the previous years. The latter also showed the higher performance to the most popular drought-tolerant released variety Sahbhagi Dhan with the predicted value of 1,562.03 (kg/ha) under stress conditions. The breeding values for popular drought-tolerant checks Vandana and 296 Rajashree were 1,391.68 (kg/ha) and $1815.65(\mathrm{~kg} / \mathrm{ha})$ under drought stress conditions 297 respectively. This depicts the superiority of the recently released lines over popular checks and 298 varieties. The genotypes were also assessed for the trials evaluated under non-stress conditions. 299 The breeding lines, IR09L204 depicted the highest breeding value of $4998.44(\mathrm{~kg} / \mathrm{ha})$ followed by IRRI 199 (4,958.74), IRRI 218 (4,900.64), IRRI 200 (4,892.13), and IRRI 188 (4,866.45) in the descending fashion of the superior performing genotypes under the non-stress conditions

302 (Fig. 3b). In the combined analysis with breeding lines performing superior under both drought 303 stress and non-stress conditions were as follows IRRI 119 (3,698.75), IRRI 163 (3,599.56), IRRI 304162 (3,395.07), IRRI 218 (3,374.91), and IRRI 200 (3374.93) (Fig. 3c). Similar to stress 305 conditions, these lines surpassed popular checks Vandana $(2,814.09)$ and Rajashree $(2,628.67)$; 306 variety Sahbhagi Dhan $(2,668.12)$. The breeding lines of the five top-performing lines have been 307 detailed in Fig. 3a-c. for stress, non-stress, and combined conditions, respectively.

\section{Identification and Development of Elite Breeding Panel}


The genotypes with higher breeding values based on the grain yield and with prediction accuracy 310 of $>0.40$ were selected for the development of the breeding core panel. In total 200 promising 311 lines were identified and used for the development of the elite panel. To make sure 200 selected 312 lines are genetically diverse and representative of decades of IRRI's drought breeding and 313 varietal development, a pedigree matrix was used to account for genetic similarity among the 314 genotypes. The relationship matrix constructed using pedigree data was visualized using the 315 biplot (Fig. 3d). From the biplot, it is very clear how diverse the selected lines are, and how they 316 represent and capture the diversity of the whole historical collection of 2,490 unique genotypes. 317 The breeding values of the 200 genotypes formulating the core panel ranged between 3,200 to $3184,622.59 \mathrm{~kg} / \mathrm{ha}$. The mean breeding value of the panel is $3,395.10$ with a standard deviation of $3193,73.23$ (Additional file 1: Fig. S7).

\section{Discussion}

321 Here we provide an overview of how 17 years of historical IRRI's rice drought data was 322 leveraged to estimate the breeding values for grain yield and estimate the genetic trends in the 323 IRRI's rice drought breeding program. We also demonstrated how the top-performing lines 324 based on the grain yield breeding values were selected as the future breeding elite resource for 325 recurrent selection-based breeding. For the selection of genotypes as a part of the core panel, 326 pedigree information availability was pivotal in fitting the additive matrix in the second stage of 327 the mixed model analysis for reliable estimation of the breeding values and help in the selection 328 of accurate genotypes for the formulation of the core panel. The essence of using the relationship 329 matrix is that it contains information about the flow of genes and explicitly allows the dissection 330 of genetic variation by accounting for the additive genetic covariances between random 331 effects/genotypes for reliable estimation of the breeding values (Piepho et al. 2008). Further, the 332 relationship matrix ties up the data across years by borrowing information from parents and 333 grandparents and creating the connectivity in the highly unbalanced data set for the reliable 334 estimation of breeding values.

\section{Genetic Trend and Breeding Value Estimations}

336 Improving the crop yield or genetic gain is crucial for minimizing the "yield gap" between the 337 breeders and farmers. The assessment of genetic gains to estimate crop yield growth has had a 338 limited focus in the past. However, genetic gain estimation with an outlook to reinforce the 
339 future breeding programs to increase genetic gain for yield has become a major focus. In this 340 study, the regression of breeding values over the year of release/testing indicated a positive 341 genetic gain under all three conditions, and the overall success of the drought breeding program 342 at IRRI. However, the genetic gain of $0.11 \%$ observed under drought conditions is not sufficient 343 to meet the current and future rice food demands. A much higher genetic gain of $1.9 \%$ was 344 reported under severe drought conditions at the reproductive stage in rice evaluated in IRRI India 345 (Kumar et al. 2021). Therefore, it is essential to optimize and modernize the drought rice 346 breeding program at IRRI for enhanced genetic gains.

347 Further we observed a minimal increase in genetic gain increase till the year 2012, post which 348 there was higher increase in genetic gain (Additional file 1: Fig.S6) which could be accredited to 349 differential breeding strategies followed in the drought breeding program across the years. The 350 drought breeding program at IRRI until 2012 was led specifically for targeting the introgression 351 of major abiotic stress-tolerant QTLs/genes for the development of NILs possessing elite genetic 352 backgrounds with minimal focus on recurrent selection breeding strategy. Thereafter, in the 353 preceding years, the focus drifted towards pyramiding these genes/QTLs for rendering multiple 354 stress-tolerant cultivars. These genotypes were not precisely targeted for genetic gain 355 enhancement; however, their genetic merit is highly valuable as these sustainable varieties were 356 disseminated for commercial cultivation across countries and can withstand additional biotic and 357 abiotic stresses along with drought. Further in the last few years more emphasize was given to 358 recurrent selection-based breeding strategies in the drought breeding program to improve the 359 yield and increase genetic gain. Rather than the QTL-based introgression or breeding approach 360 as used previously, rice breeders need to focus on population improvement breeding approaches 361 using elite lines as parents, wherein parents of each breeding cycle are selected based on high 362 additive breeding values for the grain yield. Recurrent selection schemes focused on quick 363 recycling of the best and high breeding value lines may deliver higher rates of genetic gain 364 (Cobb et al. 2019). Further to ensure the constant genetic gains, rice breeders need to select the 365 parents for new breeding cycles that have higher additive breeding value than the previous 366 breeding cycle. However, for long-term genetic gains, utmost care must be taken by the breeders 367 to diversify the elite gene pool by bringing or directly crossing the exotic or diverse materials 368 with elite pool lines. Exotic or diverse materials may broaden the elite gene pool, but they are 369 highly unadopted and unimproved lines with lower breeding values. Thus, crossing a directly 
370 diverse line with an elite line may bring novel favorable alleles and increase the genetic variance

371 of progeny, however, they barely counterbalance the mean performance of progeny due to the

372 low breeding value of diverse or exotic lines (Longin et al. 2014; Allier et al. 2020). Thus, a

373 focused recurrent selection breeding approach with a systematic pre-breeding approach is

374 required to deliver higher and constant genetic gains in IRRI's drought rice breeding program.

375 The drought breeding program at IRRI has successfully released many drought-tolerant varieties

376 across Asia and Africa (https://strasa.irri.org/), and most of them were part of this study. We

377 separately assessed the genetic gain estimation for released varieties, and higher genetic gain was 378 observed for varieties/checks released for use under drought conditions. The positive and higher 379 genetic gain $(0.55 \%)$ for checks under drought indicates that a strong impact has been made by 380 IRRI's drought breeding program to increase rice productivity under challenging and extreme 381 environments. Among these varieties- IRRI 188, IRRI 199, and IRRI 200 released during 2015 382 and 2016 had higher breeding values as compared to the popular checks Rajashree, Vandana, and 383 UPLRi7, and previously released varieties. The superiority of these lines over the formerly 384 released varieties indicates growth in grain yield to a larger extent. Also, positive genetic trend 385 and higher breeding values of the recently released varieties demarcates the positive growth of 386 the breeding program across years as the performance improved from the preceding released 387 varieties developed in the previous years. Further, among these three top-performing released 388 lines, IRRI 199 originates from a backcross breeding program utilizing a tropical japonica 389 drought and blast tolerant genotype, Moroberekan, as a donor parent and a high-yielding, semi390 dwarf Indica rice variety, Swarna. The population harbors a major, severe drought-tolerant QTL, $391 q D T Y 3.2$ contributing to various drought-tolerant traits viz., canopy cover, canopy temperature 392 (CT), root system architecture (RSA) attributes (Wasaya et al. 2018; Sofi et al. 2019). The 393 genetic region co-localizes with early flowering time QTL HD9 and lodging resistance features, 394 making the genotype suitable for various ecosystems and environments (Dixit et al. 2014; 2015). 395 Concomitantly, based on the combined analysis IRRI 163, IRRI 162, IRRI 218 and IRRI 200 396 released in the years 2011, 2015, and 2016 exhibited high breeding values under both stress and 397 non-stress conditions.

398 Development of Breeding Panel as The Future Breeding Resource 
399 In the last one-decade rice breeders at IRRI have mainly focused on introgression and 400 pyramiding of major abiotic stress-tolerant QTLs/genes in elite backgrounds (Venuprasad et al. 401 2009; Mishra et al. 2013; Yadaw et al. 2013). Population improvement based on recurrent 402 selection and early re-cycling of advanced lines has not been a major focus of the drought rice 403 breeding program at IRRI. Different crossing strategies (Additional file 1: Fig. S8) single, 404 complex, double, and backcrosses have been used by the rice breeders to integrate these QTLs 405 into the elite genetic backgrounds and develop the new breeding lines. Diverse materials, 406 including landraces, and donors have been extensively used to diversify the gene pool and 407 develop climate-resilient varieties (Sandhu et al. 2021, Yadav et al. 2021). However, this strategy 408 of diversifying the elite gene pool with limited focus on recurrent selection and early re-cycling 409 of high-value breeding lines may have limited genetic gain to a large extent and has not been 410 sufficient to maintain the higher genetic gains over time.

411 Recurrent selection with early re-cycling of lines is the key to increase the frequency of desirable 412 additive haplotypes of grain yield in each cycle, and ultimately boosting the genetic gains. To 413 strictly focus on recurrent selection breeding schemes, the presence of highly characterized elite 414 lines with higher breeding values for grain yield and possessing the key haplotypes for 415 mendelian traits is required as the base population. The historical data set used in this study 416 which contains 2,497 unique genotypes has been used by rice breeders at IRRI for decades and 417 in the past 60 years, many promising drought lines have been extracted from this breeding pool. 418 This breeding pool exhibits ample genetic diversity and possesses the key lines that may be used 419 as a future breeding resource to sustain higher grain yield under challenging environments. 420 Further, this breeding collection has not only been improved for grain yield but also 421 turbocharged with diverse alleles for important traits of biotic and abiotic stresses and represents 422 the overall diversity and breadth of IRRI's rice drought breeding program. Besides the gene bank 423 resources, this breeding pool represents the important source of genetic variation that is highly 424 dynamic created through recombination and reshuffling of alleles. Thus, identifying the high425 power performing lines based on the breeding values for grain yield that represents the overall 426 diversity of the whole breeding collections is the key to success in future recurrent selection 427 breeding strategies. To this end, we took this initiative to extract the top breeding lines from the 428 whole historical breeding collection and form the elite breeding panel as future breeding 429 resources. These selected lines besides possessing high breeding values are also indicative of 
430 higher recovery capabilities under drought stress. We believe the lines selected are the best 431 genetic variation to recombine and reshuffle in recurrent selection to increase the frequency of 432 additive haplotypes of grain yield in each cycle of breeding. Additionally, based on the literature 433 we assessed the additional characteristic features of these selected lines for resistance to biotic 434 stresses (bacterial blight, blast, brown planthoppers, stemborer, whiteheads, green leafhoppers, 435 and rice tungro virus), drought tolerance, and quality traits (Additional file 1: Table S2). It is 436 evident from the table that these lines harbor the key genes and is a readily available elite genetic 437 resource for future recurrent selection breeding schemes for targeting preferred 438 environments/countries based on the desirable market profiles.

439 Additionally, the elite panel also harbored two best performing genotypes; IR15F1706 and IR 440 54447-3B-10-2 from the 2020 drought stress trials (unpublished) showing high chlorophyll 441 fluorescence (CF) and low CT values. These genotypes when assessed had high breeding values, 442 confirming further the accuracy of the analysis undertaken. Alongside, it also demarcates that 443 deprivation in CT has a strong influence on plant's yield under drought-prone conditions. It has 444 also been reported that $\mathrm{CT}$ has a high correlation with the RSA traits symbolizing enhanced 445 genetic capacity of the plant to retain soil moisture and hence improved survival and yield under 446 drought stress conditions (Blair et al. 2010; Lopes and Reynolds 2010). Similarly, enhanced CF 447 demarcates a plant's capabilities to withstand drought stress effectively. Furthermore, two 448 multiparent conventional bred lines namely, IR 115844-B-B-281-1-2 and IR 115844-B-342-1-14491 present in the selected panel have been reported to yield more than $7000 \mathrm{~kg} / \mathrm{ha}$ under dry 450 direct-seeded conditions, with higher yields under non-stress and reproductive stage drought 451 stress conditions (Sandhu et al. 2021). In our study, these lines showed the breeding values 452 between 3200 to 3368.14 , which form a valuable resource for the breeding programs to be 453 utilized for drought-prone areas with major cultivation under dry seeded conditions having 454 limited water and labor availability. Few of the top 100 selected lines were also reported by other 455 research studies to show higher yield performance under multi-environment trials (Vergara et al. 456 2016).

457 In summary, the core breeding panel selected based on the breeding values and prediction 458 accuracy is an important genetic resource possessing multiple stress tolerance, varied range of 459 quality traits with genotypes suited for cultivation under challenging environments. Furthermore, 460 they form an easily available and highly enriched genetic resource for future recurrent selection 
461 programs and enhance genetic gains. However, we emphasize systematic genotypic and 462 phenotypic characterization of these lines in achieving more knowledge on the value proposition 463 of these lines, new allele enrichment, and help to create a framework for better understanding 464 and managing the genetic diversity in the elite pool. However, the question may arise whether 465 continued use of the elite pool lines and reshuffling of alleles in closed recurrent selection 466 strategies is enough to maintain long-term genetic gains? Most will agree with the enrichment of 467 the elite breeding pool with diverse materials as was done previously in the IRRI's drought 468 breeding program. However, we emphasize here a systematic effort to diversify the elite gene 469 pool without contaminating it with diverse materials and limiting the genetic gains (Allier et al. 470 2020).

\section{Conclusion}

472 The drought breeding program at IRRI has been successful in maintaining a positive genetic rate

473 in the breeding program, however, the increase in genetic gain has not been so high to fulfill the 474 rice food demands. To achieve the required genetic gains of $1.5 \%$ or above, a recurrent selection 475 breeding strategy of the elite population with the integration of modern tools and technologies is 476 needed. Genotypic and phenotypic characterization of the selected elite panel is required to 477 effectively manage, incorporate, and track the genetic diversity for short-term and long-term 478 genetic gains. Further, efficient pre-breeding strategies are needed to turbocharge the elite gene 479 pool with major haplotypes of traits showing discrete Mendelian segregation without 480 compromising the performance of elite lines and boost the genetic gains. 


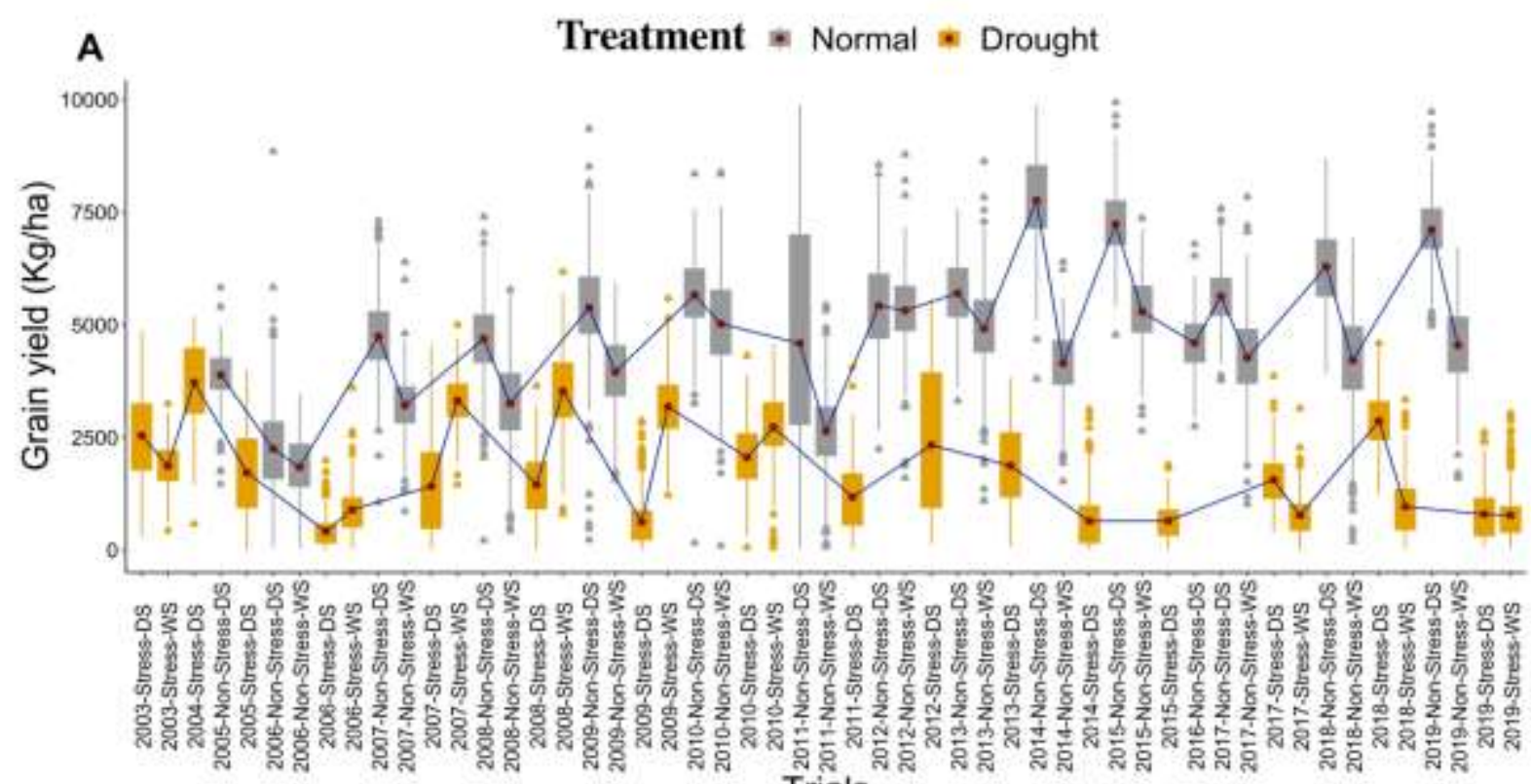

B

Treatment $\mathbf{D}$ Drought 1 Non-stress

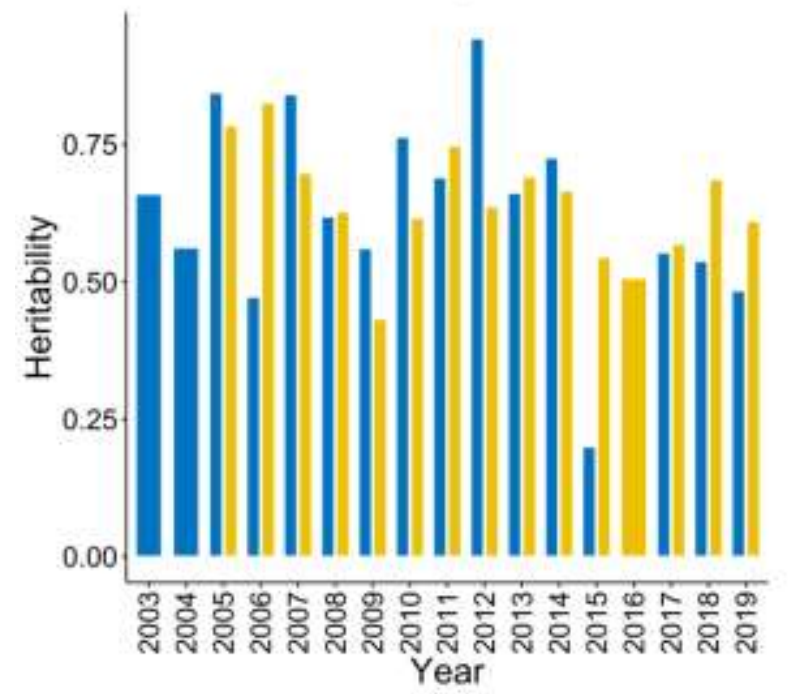

C

\section{Trials}

482

483

484

485

486

487

488

489

490

491

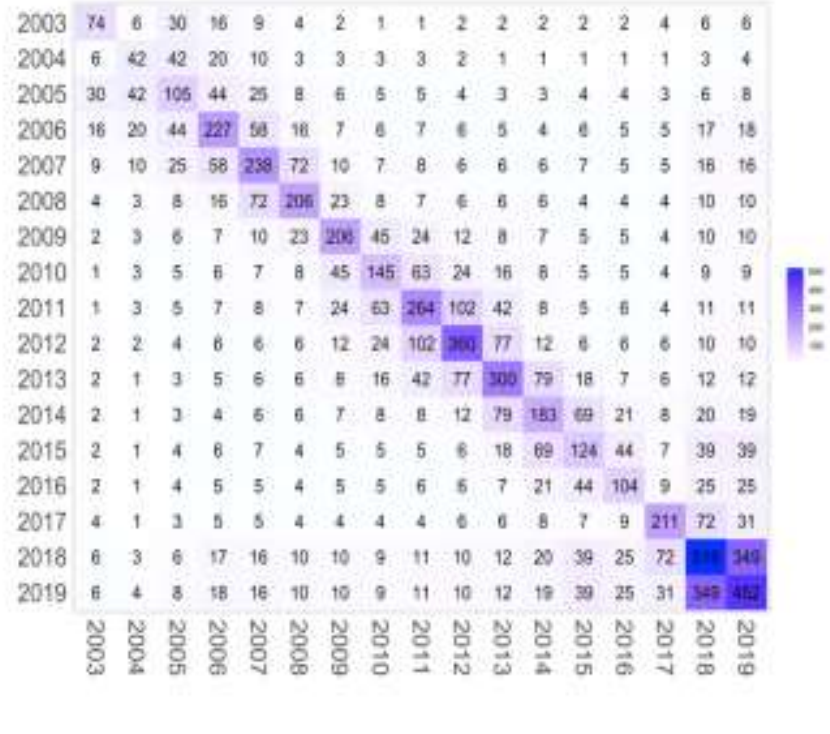

$\begin{array}{llllllllllllllllll}2003 & 74 & 6 & 30 & 16 & 9 & 4 & 2 & 1 & 1 & 2 & 2 & 2 & 2 & 2 & 4 & 6 & 6\end{array}$ $\begin{array}{llllllllllllllllllll}20005 & 30 & 42 & 105 & 44 & 25 & 8 & 6 & 6 & 5 & 5 & 4 & 3 & 3 & 4 & 4 & 3 & 6 & :\end{array}$ $\begin{array}{llllllllllllllllll}2006 & 16 & 25 & 44 & 227 & 56 & 16 & 7 & 6 & 7 & 5 & 5 & 4 & 6 & 5 & 5 & 77 & 18\end{array}$

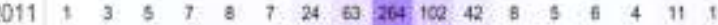

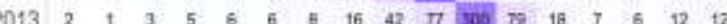

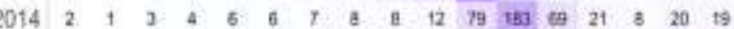
$\begin{array}{llllllllllllllllll}015 & 2 & 1 & 4 & 8 & 7 & 4 & 5 & 5 & 5 & 8 & 18 & \text { f } & 124 & 44 & 7 & 39 & 39\end{array}$ $\begin{array}{lllllllllllllllllll}2016 & 7 & 1 & 4 & 5 & 5 & 4 & 5 & 5 & 6 & 5 & 7 & 21 & 44 & 104 & 9 & 25 & 25\end{array}$

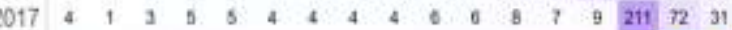

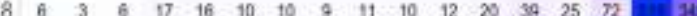

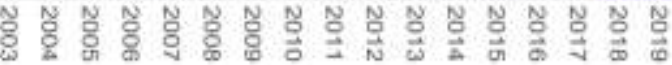

Figure 1: (a) Boxplot showing the mean grain yield $(\mathrm{kg} / \mathrm{ha})$ under normal and drought conditions from the year $2003-2019$. The $\mathrm{x}$-axis shows the trial names, which are combinations of year, season, and growing condition. In the boxplots, it is clear the grain yield is higher under normal conditions as compared to drought conditions indicating the impact of drought on the yield trials. (b). Heritabilities of the trials in each year from 2003 to 2019. The blue bars represent drought and yellow non-stress trials. (c). Connectivity of all the genotypes across years from 2003 to 2019. The genotypes including common checks and promising varieties were repeatedly tested for their performance in the successive years, thereby making the dataset well connected across successive years. The numbers in the boxes show the genotypes that were common between years. 
492
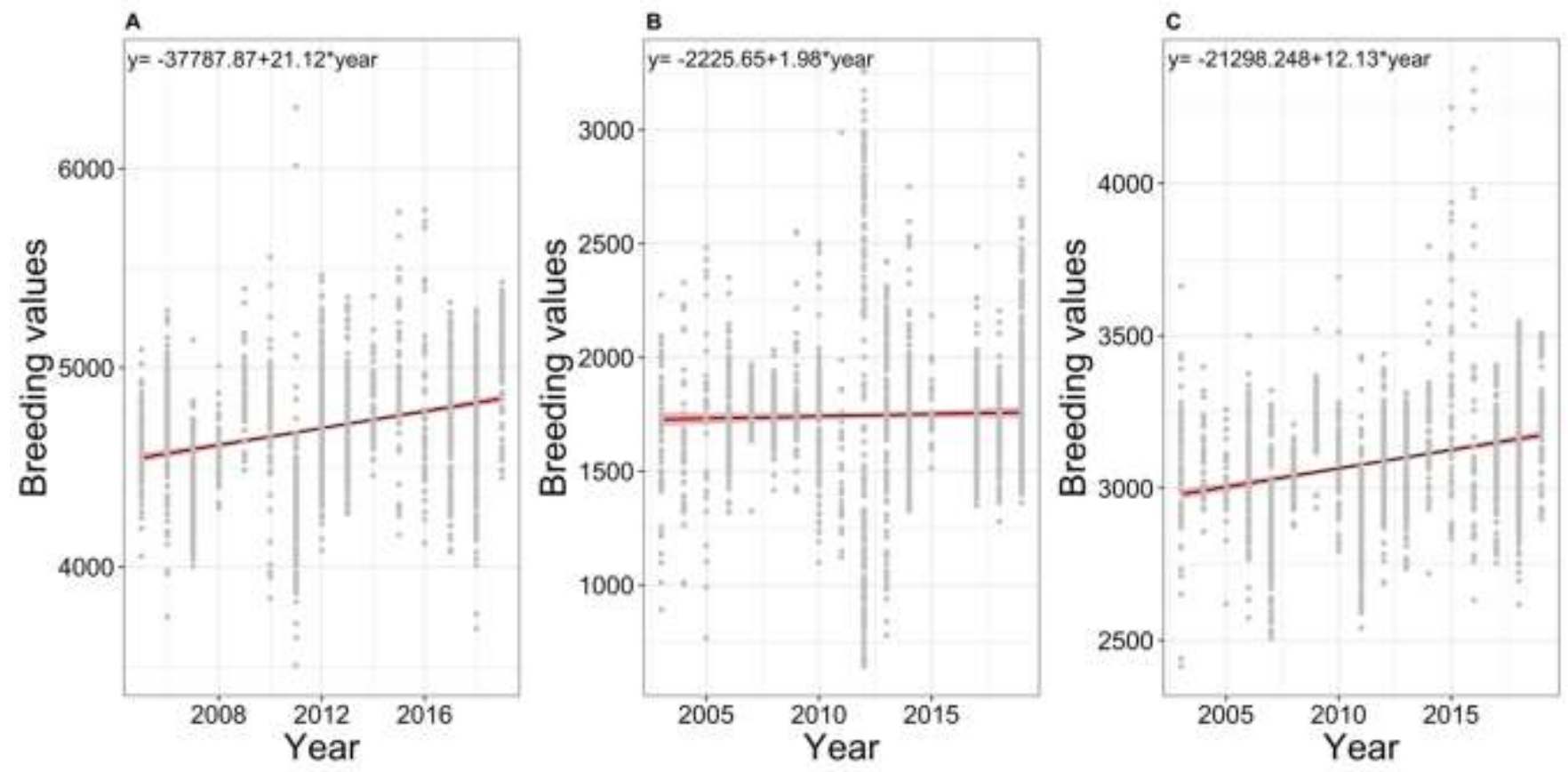

Figure 2: Trends in genetic gain from IRRI's 17 years of drought breeding program under. a) Stress conditions, b) non-stress conditions, and c) combined conditions (adjusted breeding values under stress and non-stress conditions). The X-axis shows the year of origin of the genotype and the $\mathrm{Y}$-axis shows the breeding value of the genotype. The genetic gain was estimated by regressing the breeding values of grain yield on the year of origin and is given by the slope of the line. 

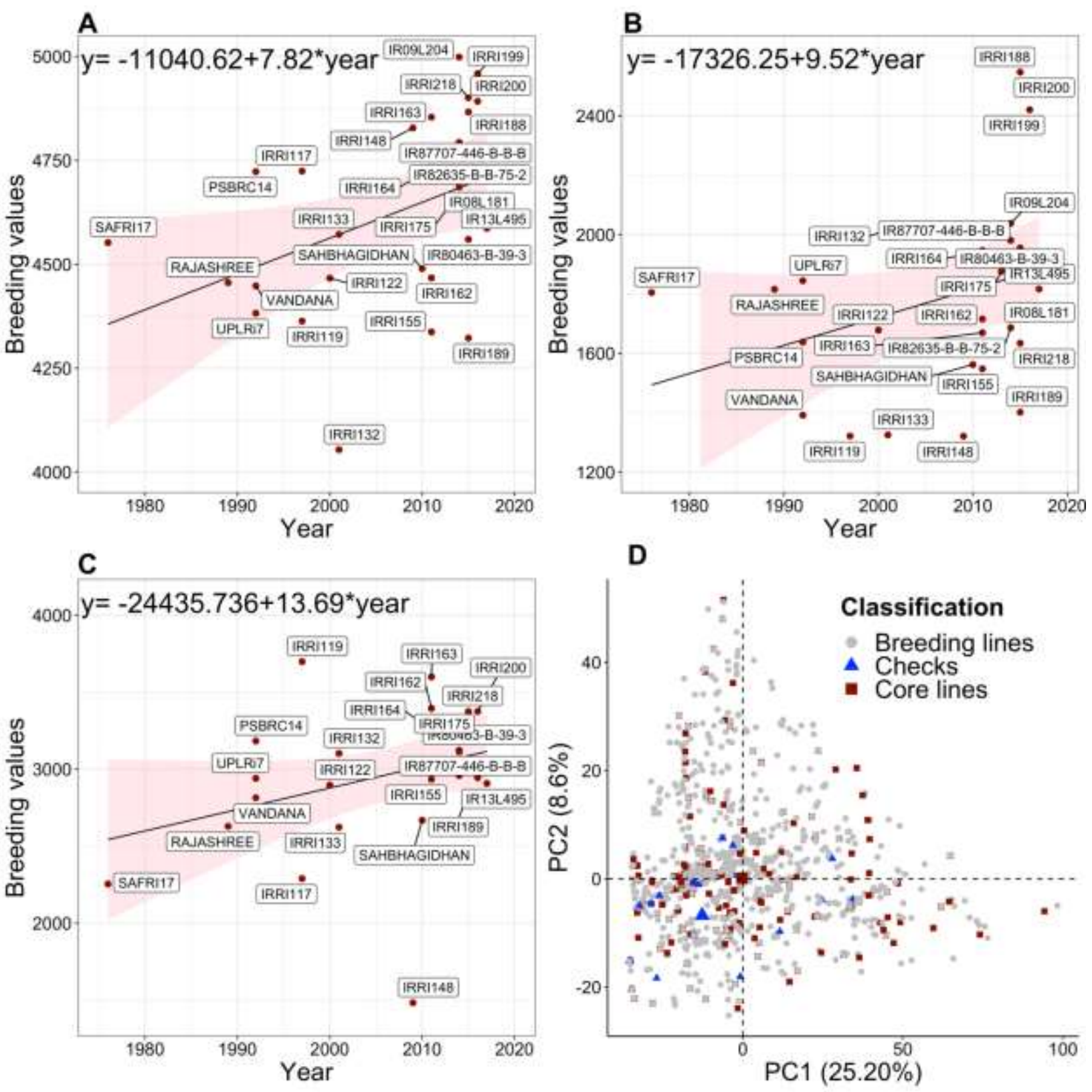

Figure 3: Trends in genetic gain for IRRI drought released lines and popular checks under three conditions: a) non-stress, b) reproductive drought and c) combined conditions. The genetic gain was estimated by regressing the breeding values on the year of origin, d) shows the biplot of the lines selected based on the breeding value for grain yield as an elite core panel. Core panel lines are highlighted in dark red color. The checks and released lines are shown in blue color, and the whole historical collection lines are represented in gray color. The biplot was constructed using the first two principal components obtained from the pedigree-based relationship matrix. The selected lines represent and capture the variability of the whole collection of genotypes and are ideal to form the core panel as a future breeding resource. 


\section{Availability of Data and Materials}

512 The datasets included in this work are given as additional files. The additional data and scripts 513 used to run the analysis can be found on the GitHub page at the following link:

514 https://github.com/whussain2/Genetic_Trend_Rice_Drought

\section{Abbreviations}

516 BLUP: Best linear unbiased predictions

517 BLUE: Best linear unbiased estimates

518 REML: Residual maximum likelihood

519 GEBV: Genomic estimated breeding values

520 CV: Coefficient of variation

521 AYT: Advanced yield trials

522 PH: Plant height

523 DTF: Days to $50 \%$ flowering

524 PCA: Principal component analysis

525 QTL: Quantitative trait loci

526 MABB: Marker-assisted backcross breeding

527 RSA: Root system architecture

528 
Ahmadikhah A, Marufinia A (2016) Effect of reduced plant height on drought tolerance in rice. 3 Biotech 6:221. https://doi.org/10.1007/s13205-016-0542-3

531 Allier A, Teyssèdre S, Lehermeier C, Lehermeier C, Moreau L, Charcosset A (2020)

532 Optimized breeding strategies to harness genetic resources with different performance levels. BMC Genomics 21:349. https://doi.org/10.1186/s12864-020-6756-0

Amadeu RR, Cellon C, Olmstead JW, Gracia AA, Resende MF, Muñoz PR (2016) AGHmatrix: $\mathrm{R}$ package to construct relationship matrices for autotetraploid and diploid species: A blueberry example. Plant Genome 9:3. https://doi.org/10.3835/plantgenome2016.01.0009

538 Bernal-Vasquez AM, Utz H-F, Piepho HP (2016) Outlier detection methods for generalized lattices: a case study on the transition from ANOVA to REML. Theor Appl Genet 129:787-804. https://doi.org/10.1007/s00122-016-2666-6

541 Bernier J, Kumar A, Ramaiah V. Spaner D, Atlin G (2007) A large-effect QTL for grain yield under reproductive-stage drought stress in upland rice. Crop Sci 47:507-516. https://doi.org/10.2135/cropsci2006.07.0495

544 Bhandari A, Sandhu N, Bartholome J, Hamadoun TV, Ahmadi N, Kumari N, Kumar A (2020)

545 Genome-wide association study for yield and yield related traits under reproductive stage drought in a diverse indica-aus rice panel. Rice 13:53. https://doi.org/10.1186/s12284-020-00406-3

548 Blair MW, González LF, Kimani PM, Butare L (2010) Genetic diversity, inter-gene pool introgression and nutritional quality of common beans (Phaseolus vulgaris L.) from

552 Butler DG, Cullis BR, Gilmour AR, Gogel BG, Thompson R (2017) ASReml-R reference manual version 4. VSN International Ltd, Hemel Hempstead, HP1 1ES, UK.

554 Cobb JN, Juma RU, Biswas PS, Juan DA, Rutkoski J, Gary A, Hagen T, Quinn M, Eng NH 555 (2019) Enhancing the rate of genetic gain in public-sector plant breeding programs: 
lessons from the breeder's equation. Theor Appl Genet 132:627-645. https://doi.org/10.1007/s00122-019-03317-0

558 Collard BCY, Gregorio GB, Thomson MJ, Islam MR, Vergara GV, Laborte AG, Nissila E, 559 Kretzschmar T, Cobb JN (2019) Transforming rice breeding: re-designing the irrigated 560 breeding pipeline at the international rice research institute (IRRI). Crop Breed Genet Genom 1:e190008. https://doi.org/10.20900/cbgg20190008

Damesa TM, Möhring J, Worku M, Piepho HP (2017) One step at a time: stage-wise analysis 563 of a series of experiments. Agronomy 109:845-857. https://doi.org/10.2134/agronj2016.07.0395

565 Dar MH, Waza SA, Shukla S, Zaidi NW, Nayak S, Hossain M, Kumar A, Ismail AM, Singh 566 US (2020) Drought tolerant rice for ensuring food security in eastern india. Sustainability 12:2214. https://doi.org/10.3390/su12062214

Dixit S, Grondin A, Lee C-R, Henry A, Olds TM, Kumar A (2015) Understanding rice adaptation to varying agro-ecosystems: trait interactions and quantitative trait loci. BMC Genet 16:86. https://doi.org/10.1186/s12863-015-0249-1

571 Dixit S, Singh A, Sta Cruz MT, Maturan PT, Amante M, Kumar A (2014) Multiple major QTL lead to stable yield performance of rice cultivars across varying drought intensities. BMC Genet 15:16. https://doi.org/10.1186/1471-2156-15-16

574 Dixit S, Singh UM, Singh AK, Alam S, Challa V, Nachimuthu VV, Yadav S, Abbai R, 575 Selvaraj R, Devi MN, Ramayya PJ, Badri J, Ram T, Lakshmi J, Lakshmidevi G, 576 Vidhya LRK, Padmakumari AP, Laha GS, Prasad MS, Seetalam M, Singh VK, Kumar A (2020) Marker assisted forward breeding to combine multiple biotic-abiotic stress

579 Dixit S, Yadaw RB, Mishra KK, Kumar A (2017) Marker-assisted breeding to develop the drought-tolerant version of Sabitri, a popular variety from Nepal. Euphytica 213:184. https://doi.org/10.1007/s10681-017-1976-3

582 FAO (2019) The State of Food and Agriculture 2019. Moving forward on food loss and waste 583 reduction. Rome. Licence: CC BY-NC-SA 3.0 IGO. 
Gonzalez MY, Weise S, Zhao Y, Philipp N, Arend D, Börner A, Oppermann M, Graner A, Reif JC, Schulthess AW (2018) Unbalanced historical phenotypic data from seed regeneration of a barley ex situ collection. Sci Data 5:180278. https://doi.org/10.1038/sdata.2018.278

588

589

590

591

592

593

594

595

596

597

598

599

600

601

602

603

604

605

606

607

608

609

610

611

Henry A, Stuart-Williams H, Dixit S, Kumar A, Farquhar G (2019) Stomatal conductance responses to evaporative demand conferred by rice drought-yield quantitative trait locus qDTY12.1. Functional Plant Biol 46:660-669. https://doi.org/10.1071/FP18126

Henry A, Swamy BPM, Dixit S, Torres RD, Batoto TC, Manalili M, Anantha MS, Mandal NP, Kumar A (2015) Physiological mechanisms contributing to the QTL-combination effects on improved performance of IR64 rice NILs under drought. J Exp Bot 66:1787-1799. https://doi.org/10.1093/jxb/eru506

Henry T, Nguyen R, Chandra Babu, Blum A (1997) Breeding for Drought Resistance in Rice: Physiology and Molecular Genetics Considerations. Crop Sci 37: 1426-1434. https://doi.org/10.2135/cropsci1997.0011183X003700050002x

Hussain HA, Hussain S, Khaliq A, Ashraf U, Anjum SA, Men S, Wang L (2018) Chilling and drought stresses in crop plants: implications, cross talk, and potential management opportunities. Front Plant Sci 9:393 https://doi.org/10.3389/fpls.2018.00393

Isik F, Holland J, Maltecca C (2017) Spatial Analysis. In: Genetic Data Analysis for Plant and Animal Breeding. Springer International Publishing, Cham, pp 203-226

Kassambara A, Mundt F (2017) Package "factoextra" for R: Extract and Visualize the Results of Multivariate Data Analyses. R Package. version 2017, 1-77.

Kazan K, Lyons R (2016) The link between flowering time and stress tolerance. J Exp Bot 67:47-60. https://doi.org/10.1093/jxb/erv441

Kumar A, Dixit S, Ram T, Yadaw RB, Mishra KK, Mandal NP (2014) Breeding high-yielding drought-tolerant rice: genetic variations and conventional and molecular approaches. J Exp Bot 65:6265-6278. https://doi.org/10.1093/jxb/eru363

Kumar A, Raman A, Yadav S, Verulkar SB, Mandal NP, Singh ON, Swain P, Ram T, Badri J, Dwivedi JL, Das SP, Singh SK, Singh SP, Kumar S, Jain A, Chandrababu R, Robin S, 
Shashidhar HE, Hittalmani S, Satyanarayana P, Venkateshwarlu C, Ramayya J, Naik S, Nayak S, Dar MH, Hossain SM, Henry A, Piepho HP (2021) Genetic gain for rice yield in rainfed environments in India. Field Crops Res 260:107977. https://doi.org/10.1016/j.fcr.2020.107977

Kumar A, Sandhu N, Dixit S, Yadav S, Swamy BM, Shamsudin NAA (2018) Marker-assisted selection strategy to pyramid two or more QTLs for quantitative trait-grain yield under drought. Rice 11:35. https://doi.org/10.1186/s12284-018-0227-0

Kumar A, Sandhu N, Venkateshwarlu C, Priyadarshi R, Yadav S, Majumder RR, Singh VK (2020) Development of introgression lines in high yielding, semi-dwarf genetic backgrounds to enable improvement of modern rice varieties for tolerance to multiple abiotic stresses free from undesirable linkage drag. Sci Rep 10:13073. https://doi.org/10.1038/s41598-020-70132-9

Kumar R, Venuprasad R, Atlin GN (2007) Genetic analysis of rainfed lowland rice drought tolerance under naturally-occurring stress in eastern India: Heritability and QTL effects. Field Crops Res 103:42-52. https://doi.org/10.1016/j.fcr.2007.04.013.

Lenaerts B, Collard BCY, Demont M (2019) Review: Improving global food security through $\begin{array}{llll}\text { accelerated plant breeding. Plant } & \text { 287:110207. }\end{array}$ https://doi.org/10.1016/j.plantsci.2019.110207

Li H, Rasheed A, Hickey LT, He Z (2018) Fast-forwarding genetic gain. Trends Plant Sci 23:184-186. https://doi.org/10.1016/j.tplants.2018.01.007

Longin CFH, Reif JC (2014) Redesigning the exploitation of wheat genetic resources. Trends Plant Sci 19:631-636. https://doi.org/10.1016/j.tplants.2014.06.012

Lopes MS, Reynolds MP (2010) Partitioning of assimilates to deeper roots is associated with cooler canopies and increased yield under drought in wheat. Functional Plant Biol 37:147-156. https://doi.org/10.1071/FP09121

Majumder RR, Sakhale S, Yadav S, Sandhu N, Hassan L, Hossain MA, Kumar A. (2021) Molecular breeding for improving drought tolerance in rice: recent progress and future perspectives. In: Hossain MA, Hassan L, Ifterkharuddaula KM, Kumar A, Henry R 
(eds) Molecular breeding for rice abiotic stress tolerance and nutritional quality. John Wiley \& Sons Ltd. Pp 53-74. https://doi.org/10.1002/9781119633174.ch3

642 McLaren CG, Bruskiewich RM, Portugal AM, Cosico AB (2005) The international rice information system. a platform for meta-analysis of rice crop data. Plant Physiol 139:637-642. https://doi.org/10.1104/pp.105.063438

Mishra KK, Vikram P, Yadaw RB, Swamy BM, Dixit S, Sta Cruz MT, Paul M, Marker S, Kumar A (2013) qDTY12.1: a locus with a consistent effect on grain yield under drought in rice. BMC Genet 14:12. https://doi.org/10.1186/1471-2156-14-12

Mishra SS, Panda D (2017) Leaf traits and antioxidant defense for drought tolerance during early growth stage in some popular traditional rice landraces from Koraput, India. Rice Sci 24:207-217. https://doi.org/10.1016/j.rsci.2017.04.001

Möhring J, Piepho HP (2009) Comparison of weighting in two-stage analysis of plant breeding trials. Crop Sci 49:1977-1988. https://doi.org/10.2135/cropsci2009.02.0083

Muthu V, Abbai R, Nallathambi J, Rahman H, Ramasamy S, Kambale R, Thulasinathan T, Ayyenar B, Muthurajan R (2020) Pyramiding QTLs controlling tolerance against drought, salinity, and submergence in rice through marker assisted breeding. PLoS ONE 15:e0227421. https://doi.org/10.1371/journal.pone.0227421

659 Pandey S, Bhandari H, Ding S, Prapertchob P, Sharan R, Naik D, Taunk SK, Sastri A (2007)

Peng S, Huang J, Sheehy JE, Laza RC, Romeo M, Visperas, Zhong X, Centeno GS, Khush GS, Coping with drought in rice farming in Asia: insights from a cross-country comparative study. Agric Econ 37:213-224. https://doi.org/10.1111/j.1574Cassman KG (2004) Rice yields decline with higher night temperature from global warming. PNAS 101:9971-9975

Philipp N, Weise S, Oppermann M, Börner A, Keilwagen J, Kilian B, Arend D, Zhao Y, Graner A, Reif JC, Schulthess AW (2019) Historical phenotypic data from seven 
decades of seed regeneration in a wheat ex situ collection. Sci Data 6:137. https://doi.org/10.1038/s41597-019-0146-y

670 Piepho HP, Möhring J (2007) Computing Heritability and Selection Response From 671 Unbalanced Plant Breeding Trials. Genetics 177:1881-1888. 672 https://doi.org/10.1534/genetics.107.074229

673 Piepho HP, Möhring J, Melchinger AE, Büchse A (2008) BLUP for phenotypic selection in 674 plant breeding and variety testing. Euphytica 161:209-228. https://doi.org/10.1007/s10681-007-9449-8

676 Piepho HP, Möhring J, Schulz-Streeck T, Ogutu JO (2012) A stage-wise approach for the 677 analysis of multi-environment trials. Biom J 54:844-860. https://doi.org/10.1002/bimj.201100219

679 R Core Team (2020) R: A language and environment for statistical computing. R foundation for statistical computing, Vienna, Austria. https://www.R-project.org/

Sandhu N, Dixit S, Swamy BPM, Raman A, Kumar S, Singh SP, Yadaw RB, Singh ON, Reddy JN, Anandan A, Yadav S, Venkataeshwarllu C, Henry A, Verulkar S, Mandal NP, Ram T, Badri J, Vikram P, Kumar A (2019) Marker assisted breeding to develop multiple stress tolerant varieties for flood and drought prone areas. Rice 12:8. https://doi.org/10.1186/s12284-019-0269-y

Sandhu N, Kumar A (2017) Bridging the rice yield gaps under drought: QTLs, genes, and their use in breeding programs. Agronomy 7:27. https://doi.org/10.3390/agronomy7020027

Sandhu N, Singh A, Dixit S, Sta Cruz MT, Maturan PC, Jain RK, Kumar A (2014) Identification and mapping of stable QTL with main and epistasis effect on rice grain 2156-15-63 
Shavrukov Y, Kurishbayev A, Jatayev S, Shvidchenko V, Zotova L, Koekemoer F, de Groot S, Soole K, Langridge P (2017) Early flowering as a drought escape mechanism in plants: how can it aid wheat production?. Front Plant Sci 8:1950. https://doi.org/10.3389/fpls.2017.01950

Smith AB, Cullis BR (2018) Plant breeding selection tools built on factor analytic mixed models for multi-environment trial data. Euphytica 214:143. https://doi.org/10.1007/s10681-018-2220-5

Sofi P, Ara A, Gull M, Rehman K (2019) Canopy temperature depression as an effective physiological trait for drought screening, drought - detection and solutions, Gabrijel Ondrasek, IntechOpen, https://doi.org/10.5772/intechopen.85966 Accessed 5 Aug 2021

STRASA Legacy site - Climate-smart rice. https://strasa.irri.org/. Accessed 5 Aug 2021

STRASA Legacy site - Climate-smart rice. https://strasa.irri.org/varietal-releases/drought.

Van oort PAJ, Zwart SJ (2018) Impacts of climate change on rice production in Africa and causes of simulated yield changes. Glob Change Biol. 24:1029- 1045. https://doi.org/10.1111/gcb.13967

Venuprasad R, Dalid CO, Del Valle M, Zhao D, Espiritu M, Sta Cruz MT, Amante M, Kumar A, Atlin GN (2009) Identification and characterization of large-effect quantitative trait loci for grain yield under lowland drought stress in rice using bulk-segregant analysis. Theor Appl Genet 120(1):177-90. https://doi.org/10.1007/s00122-009-1168-1

Vergara GV, Collard BCY, Pamplona A, Gregorio GB (2016). Fast-tracking rice varietal testing and adoption in different ecosystems in the Philippines. In: 36th Rice Technical Working Group (RTWG) meeting, Galveston, Texas, US. https://doi.org/10.13140/RG.2.1.2575.2727

Vikram P, Swamy BM, Dixit S, Ahmed HU, Sta Cruz MT, Singh AK, Kumar A (2011) qDTY1.1, a major QTL for rice grain yield under reproductive-stage drought stress with a consistent effect in multiple elite genetic backgrounds. BMC Genet 12:89. https://doi.org/10.1186/1471-2156-12-89 
Wasaya A, Zhang X, Fang Q, Yan Z (2018) Root phenotyping for drought tolerance: a review. Agronomy 8(11):241. https://doi.org/10.3390/agronomy8110241

725 Wing RA, Purugganan MD, Zhang Q (2018) The rice genome revolution: from an ancient grain to green super rice. Nat Rev Genet 19:505-517. https://doi.org/10.1038/s41576$\underline{018-0024-Z}$

\section{Acknowledgements}

740 We express profound gratitude to the Bill and Melinda Gates Foundation to fund this research 741 study. Special thanks to Hans Bhardwaj (Platform Leader, Rice Breeding Innovations, IRRI) for

742 his guidance and all the support. Authors also thank IRRI rainfed breeding program breeders

743 Gary Atlin, Arvind Kumar and Shalabh Dixit who all had conducted these trials since 2003 and 744 generate the data used in this study. We also thanks Jessica Rutkoski a former IRRI biometrician 745 who initiated the genetic gain study in the IRRI's drought breeding program and we adopted 746 some of the R scripts from her work.

\section{Funding}

748 The study was supported by the AGGRi Alliance project, "Accelerated Genetic Gains in Rice 749 Alliance" funded by the Bill and Melinda Gates Foundation. 
751 Affiliations

752 Rice Breeding Innovation Platform, International Rice Research Institute (IRRI), LoS 753 Banos, Laguna 4031, Philippines

754 Apurva Khanna, Mahender Anumalla, Margaret Catolos, Jérôme Bartholomé, Roberto Fritsche755 Neto, John Damien Platten, Daniel Joseph Pisano, Alaine Gulles, Ma Teresa Sta. Cruz, Joie 756 Ramos, Gem Faustino, Sankalp Bhosale, Waseem Hussain

757 CIRAD, UMR AGAP, Montpellier, France, AGAP, Univ Montpellier, CIRAD, INRA, 758 Montpellier SupAgro, Montpellier, France.

759 Jérôme Bartholomé

761 Author contributions

$762 \mathrm{WH}$ and SB designed the study, conceived the concept, and provided overall guidance in 763 conducting the study. AK and WH performed all the statistical analysis. AK wrote the initial 764 draft of the manuscript. MA and MC helped in data collections, analysis and drafting the 765 manuscript. JB, RFN and JDP helped in editing and reviewing the manuscript and provided 766 overall guidance in the data analysis. JB, DJP and AG helped in the data analysis and extraction 767 of pedigrees for data. TSC, JR and GF helped in data collections and drafting the manuscript. All 768 the authors read, reviewed, and approved the final manuscript.

769 Corresponding author

770 Waseem Hussain

771 International Rice Research Institute (IRRI), Los Baños, Laguna 4031, Philippines,

772 email: waseem.hussain@irri.org

774 Ethics declarations

775 Ethics approval and consent to participate

776 Not applicable

777 Competing interests

778 The authors declare that they have no competing interests.

779 Publisher's Note 
781 Genetic Trends Estimation in IRRIs Rice Drought Breeding Program and Identification of 782 High Yielding Drought-tolerant Lines

783 Apurva Khanna ${ }^{1}$, Mahender Anumalla ${ }^{1}$, Margaret Catolos ${ }^{1}$, Jerome Bartholome ${ }^{2}$, Roberto 784 Fritsche-Neto ${ }^{1}$, John Damien Platten ${ }^{1}$ Daniel Joseph Pisano ${ }^{1}$, Alaine Gulles ${ }^{1}$, Ma Teresa Sta. 785 Cruz $^{1}$, Joie Ramos ${ }^{1}$, Gem Faustino ${ }^{1}$, Sankalp Bhosale ${ }^{1}$, Waseem Hussain ${ }^{1 *}$

$786{ }^{1}$ Rice Breeding Innovation Platform, International Rice Research Institute (IRRI), Los Banos, 787 Laguna, Philippines

$788{ }^{2}$ CIRAD, UMR AGAP, Montpellier, France, AGAP, Univ Montpellier, CIRAD, INRA, 789 Montpellier SupAgro, Montpellier, France

790

* Corresponding author:

Waseem Hussain

793 International Rice Research Institute (IRRI), Los Baños, Laguna 4031, Philippines,

794 email: waseem.hussain@irri.org

795

796

Additional file 1: Figure S1: Boxplots showing distribution of raw data values for days to 50\%

797 flowering (DTF) data under non-stress and drought conditions.

798 Additional file 1: Figure S2: Boxplots showing the distribution of raw data values for plant 799 height $(\mathrm{cm})$ data under non-stress and drought conditions.

800 Additional file 1: Figure S3: Depiction of the number of same genotypes tested across the years 801 in the breeding program.

802 Additional file 1: Figure S4: Pedigree-based heat map and clustering of the genotypes bred over 803 the years.

804 Additional file 1: Figure S5: Distribution of the breeding values for grain yield.

805 Additional file 1: Figure S6: Shows genetic trends from the year 2005- 2012 under non-stress 806 conditions, b) shows genetic trends from the year 2013- 2019 under non-stress conditions, c) 807 shows genetic trends from the year 2003- 2012 under stress conditions, and d) shows genetic 
808 trends from the year 2013- 2019 under stress conditions. Both under non-stress and stress 809 conditions higher genetic gain was observed post to year 2012.

810 Additional file 1: Figure S7: Distribution of 200 selected genotypes for grain yield breeding 811 values.

812 Additional file 1: Figure S8: Breeding schemes implemented each year in the drought breeding 813 program from the year 2003-2019.

814 Additional file 1: Table S1: List of trials used in this study for genetic trend estimations and 815 formulation of elite core panel.

816 Additional file 1: Table S2: Delineation of the traits and characteristics of top performing 817 genotypes formulating the breeding panel. 


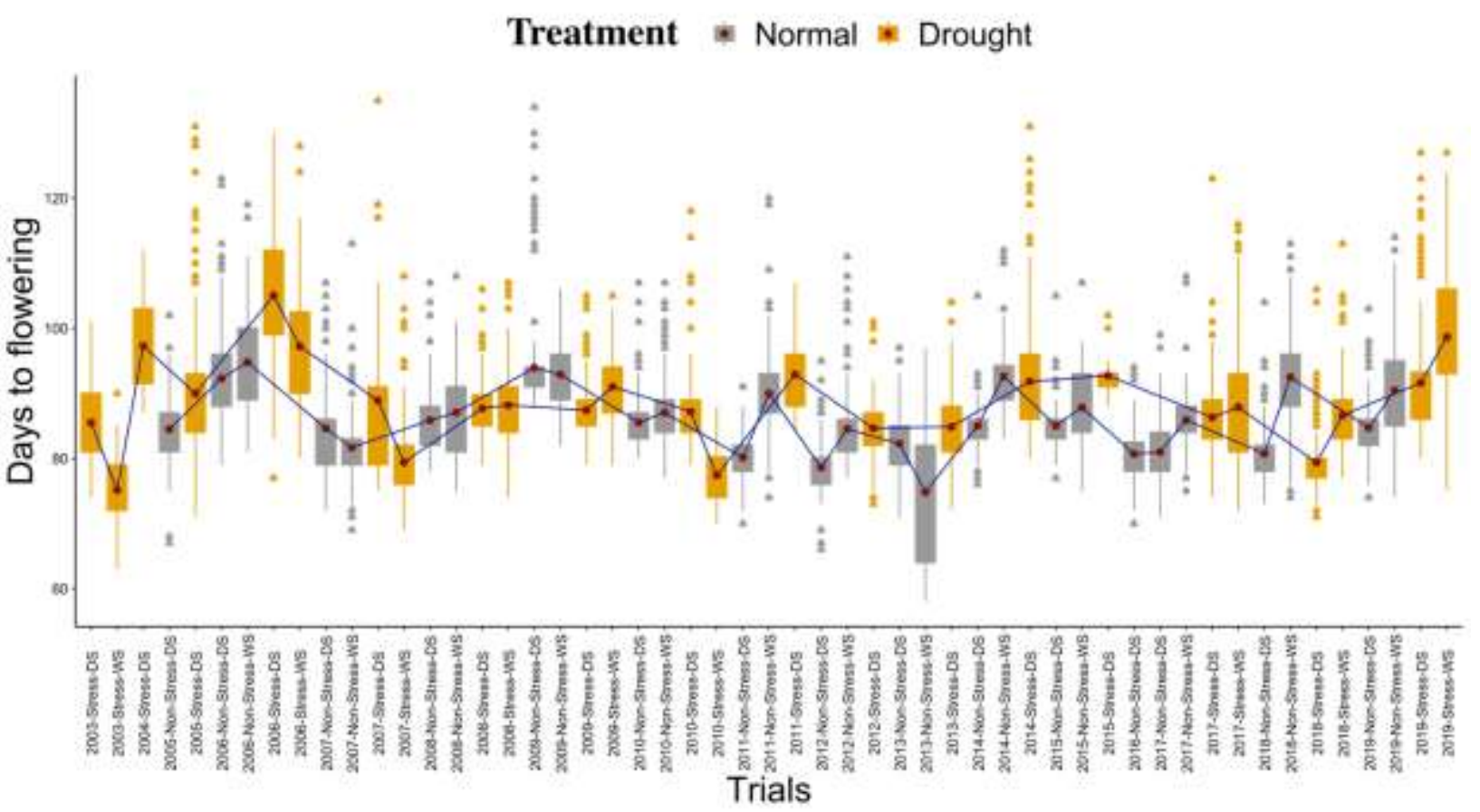

Figure S1: Boxplots showing the raw days to $50 \%$ flowering (DTF) data under non-stress 820 (normal) conditions and drought conditions from the year 2003-2019. The Plant height values of 821 the non-stress trials are illustrated in gray, as a comparison to the Plant height values of the stress 822 trials denoted in orange. 


\section{Treatment * Normal * Drought}

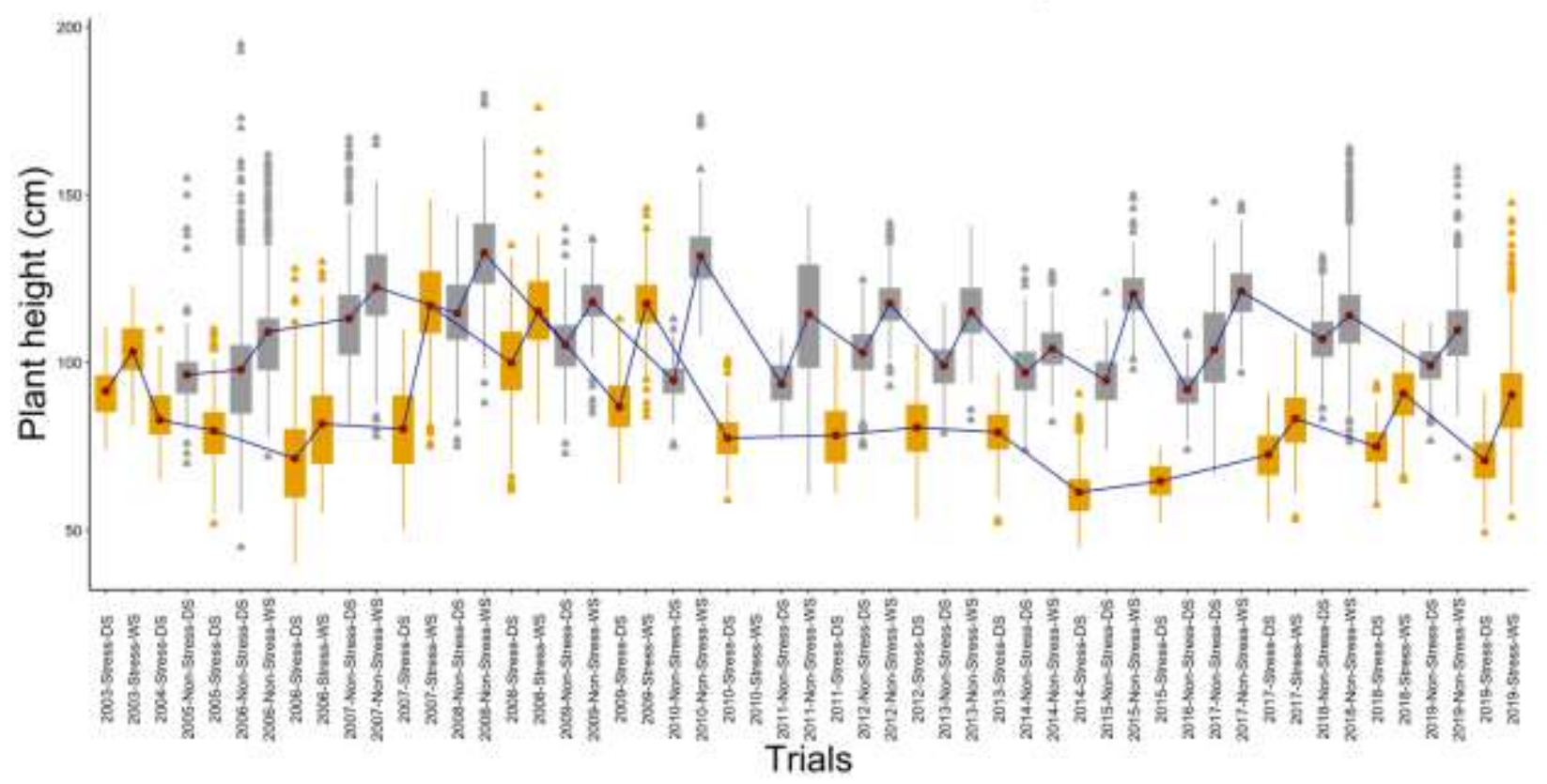

823

824

825

826

827
Figure S2: Boxplots showing the raw plant height $(\mathrm{cm})$ data under non-stress (normal) conditions and drought conditions from the year 2003-2019. The plant height values of the nonstress trials are illustrated in gray, as a comparison to the plant height values of the stress trials denoted in orange. 


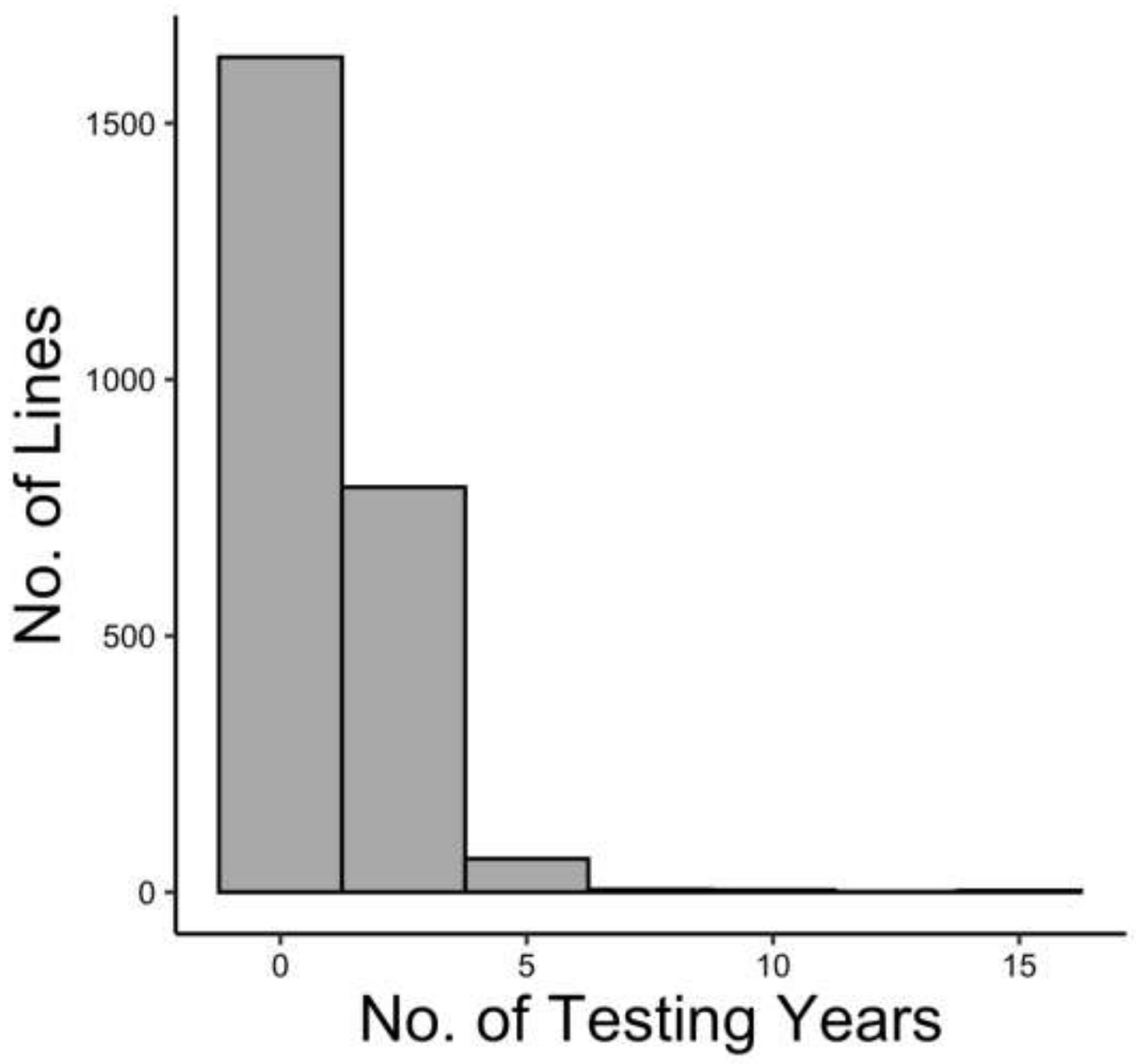

Figure S3: The figure depicts the number of the same genotypes tested across the years. It is 830 apparent from the figure that a limited number of genotypes were evaluated for more than one 831 year. Less than 50 genotypes were evaluated for more than two years. 


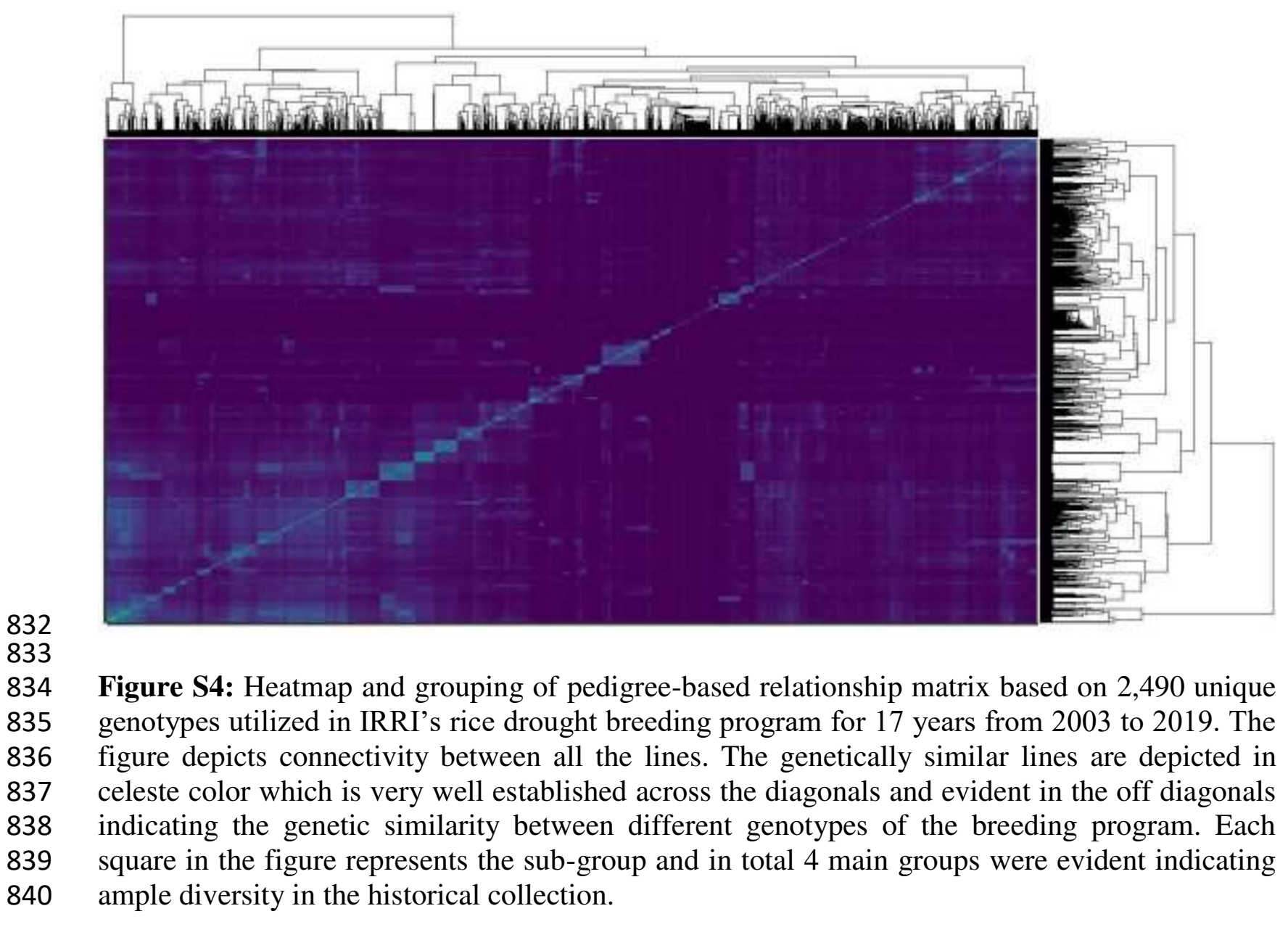



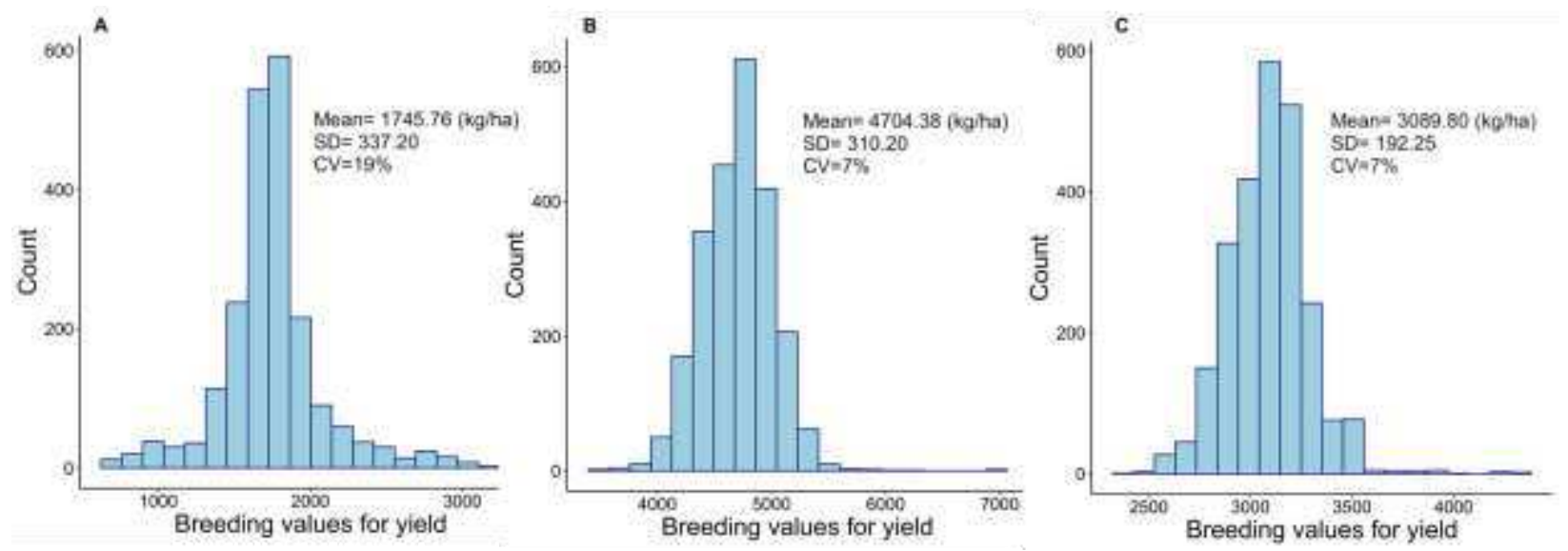

843 Figure S5: Distribution of the breeding values for grain yield $(\mathrm{kg} / \mathrm{ha})$ under three conditions: a) 844 Stress, b) Non-Stress, and c). Combined stress and non-stress. 

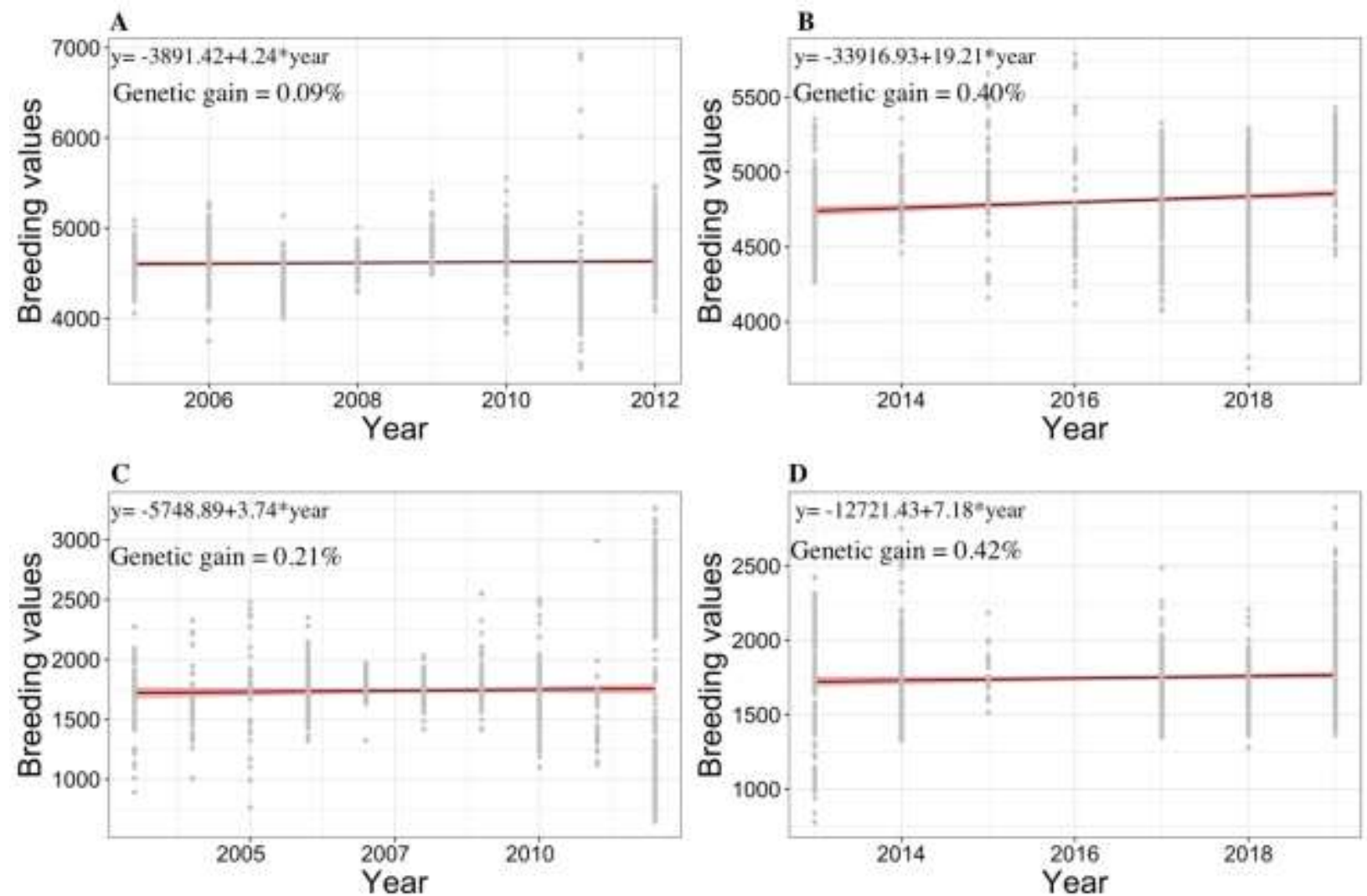

846

847

848

849

850

851

Figure S6: a) Shows genetic trends from the year 2005- 2012 under non-stress conditions, b) shows genetic trends from the year 2013- 2019 under non-stress conditions, c) shows genetic trends from the year 2003- 2012 under stress conditions, and d) shows genetic trends from the year 2013- 2019 under stress conditions. Both under non-stress and stress conditions higher genetic gain was observed post to year 2012 . 


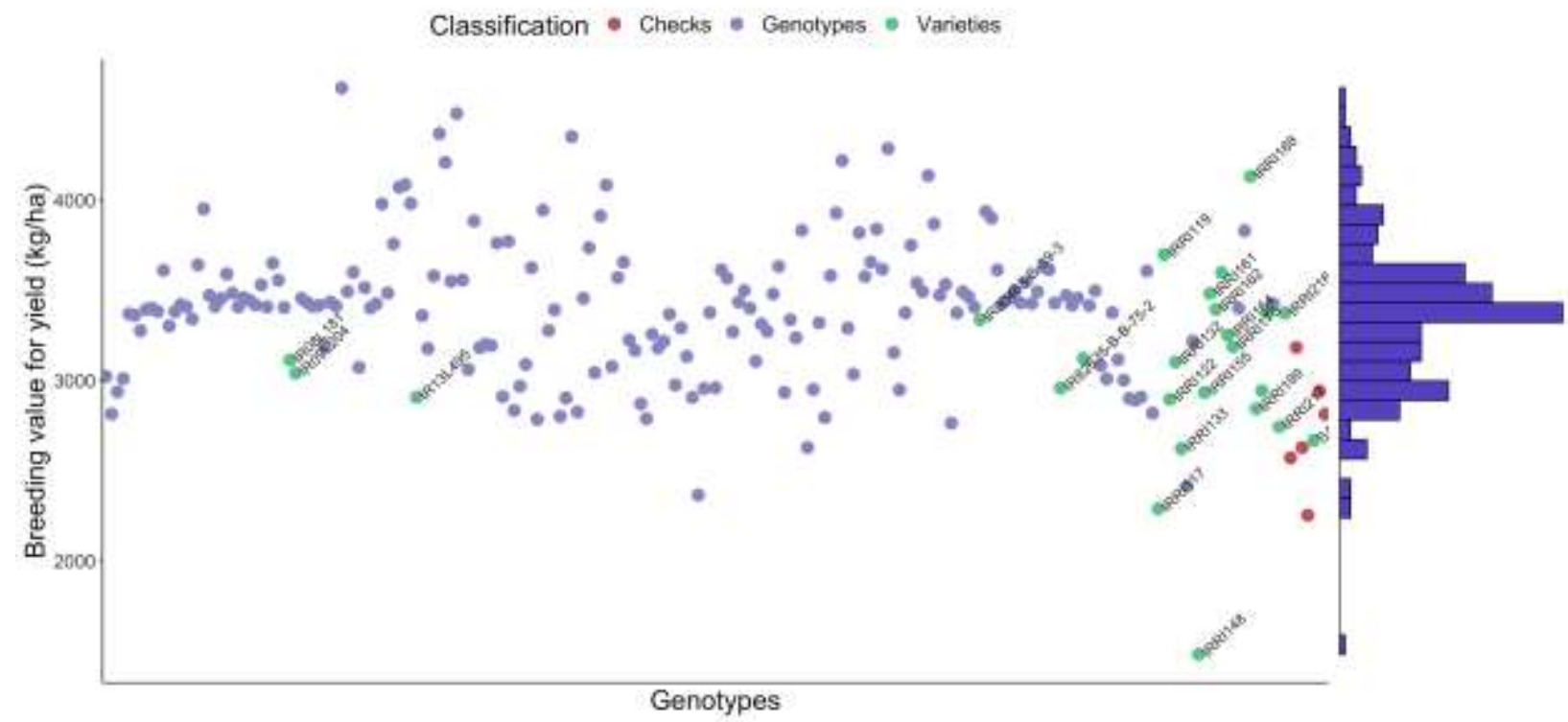
853 Figure S7: Representation of the distribution of genotypes comprising the breeding panel. The
854 genotypes include superior genotypes with high breeding values and reliabilities along with 855 additional traits for tolerance to biotic abiotic stresses with superior grain and cooking quality 856 traits. The blue dots represent the selected breeding panel lines which as depicted by the figure 857 have higher or comparable breeding values compared to the drought-tolerant checks in red and 858 IRRI released varieties in green dots, respectively. 


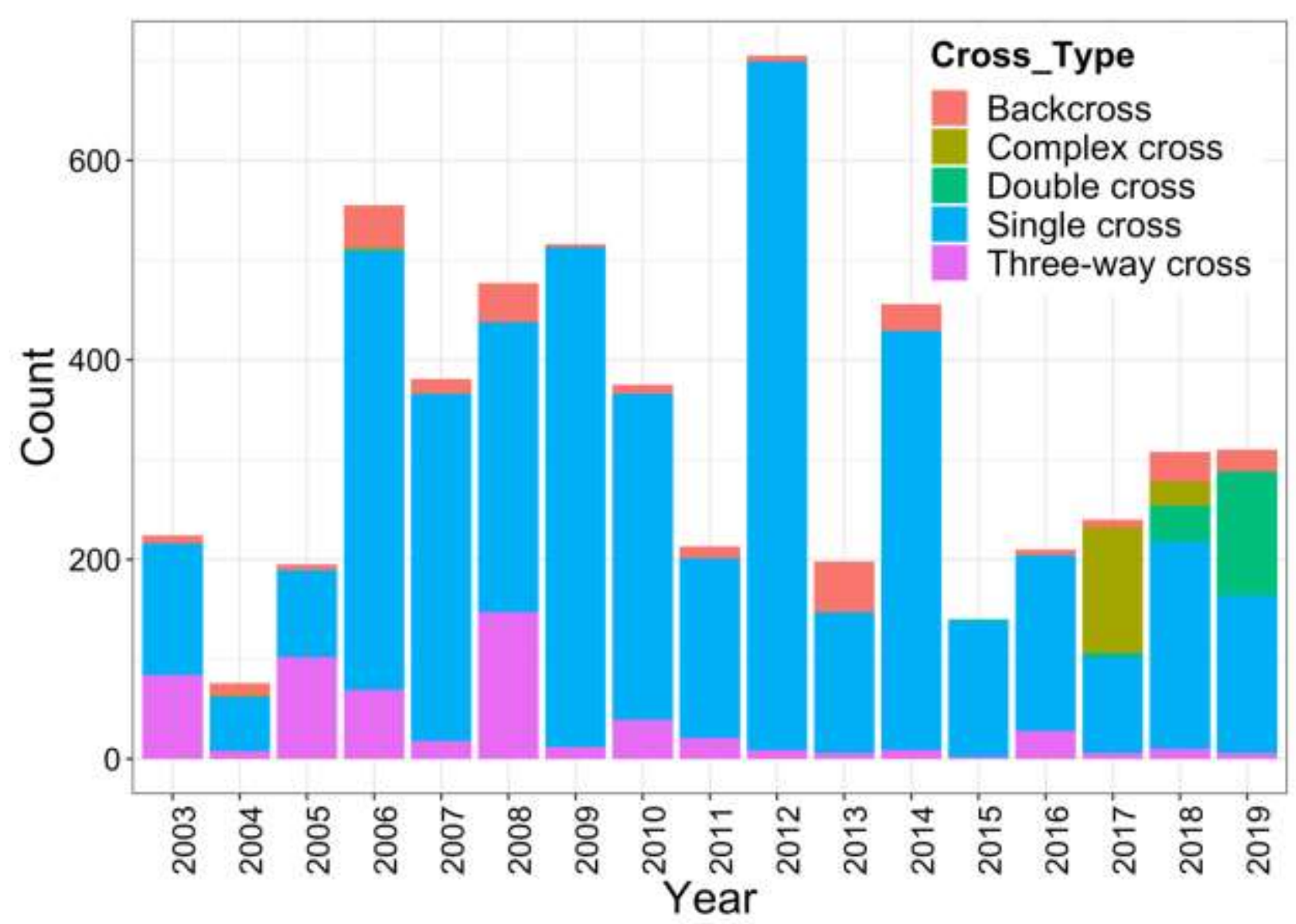

Figure S8: The information stating year-wise classification of genotypes developed through 861 various breeding strategies from the year 2003-2019. Mixed types of crossing strategies were 862 adopted by the breeders. In later years more backcross and complex crosses were made. 


\section{Supplementary Files}

This is a list of supplementary files associated with this preprint. Click to download.

- SupplementaryTables.xlsx 